\title{
A Conceptual Study of a Transonic NLF Transport Aircraft with Forward Swept Wings
}

\author{
Martin Kruse ${ }^{1}$, Tobias Wunderlich ${ }^{2}$ and Lars Heinrich. ${ }^{3}$ \\ German Aerospace Center (DLR), Braunschweig, Germany, 38114
}

\begin{abstract}
DLR's concept for a natural laminar flow transonic transport aircraft with forward swept wings is presented. Giving an overview on the aircraft's configurational layout first, the focus is on the multidisciplinary design of NLF wing and its aerodynamic performance. Results from high-fidelity coupled aero-structural simulations show that a significant extent of laminar flow is achievable. Torsional divergence of the wing is successfully suppressed by aeroelastic tailoring. The impact of elastic wing deformation on boundary layer stability and NLF performance is studied. Finally, results of the aircraft's cruise performance and expected fuel savings are provided and compared to results from preliminary design.
\end{abstract}

\section{Nomenclature}

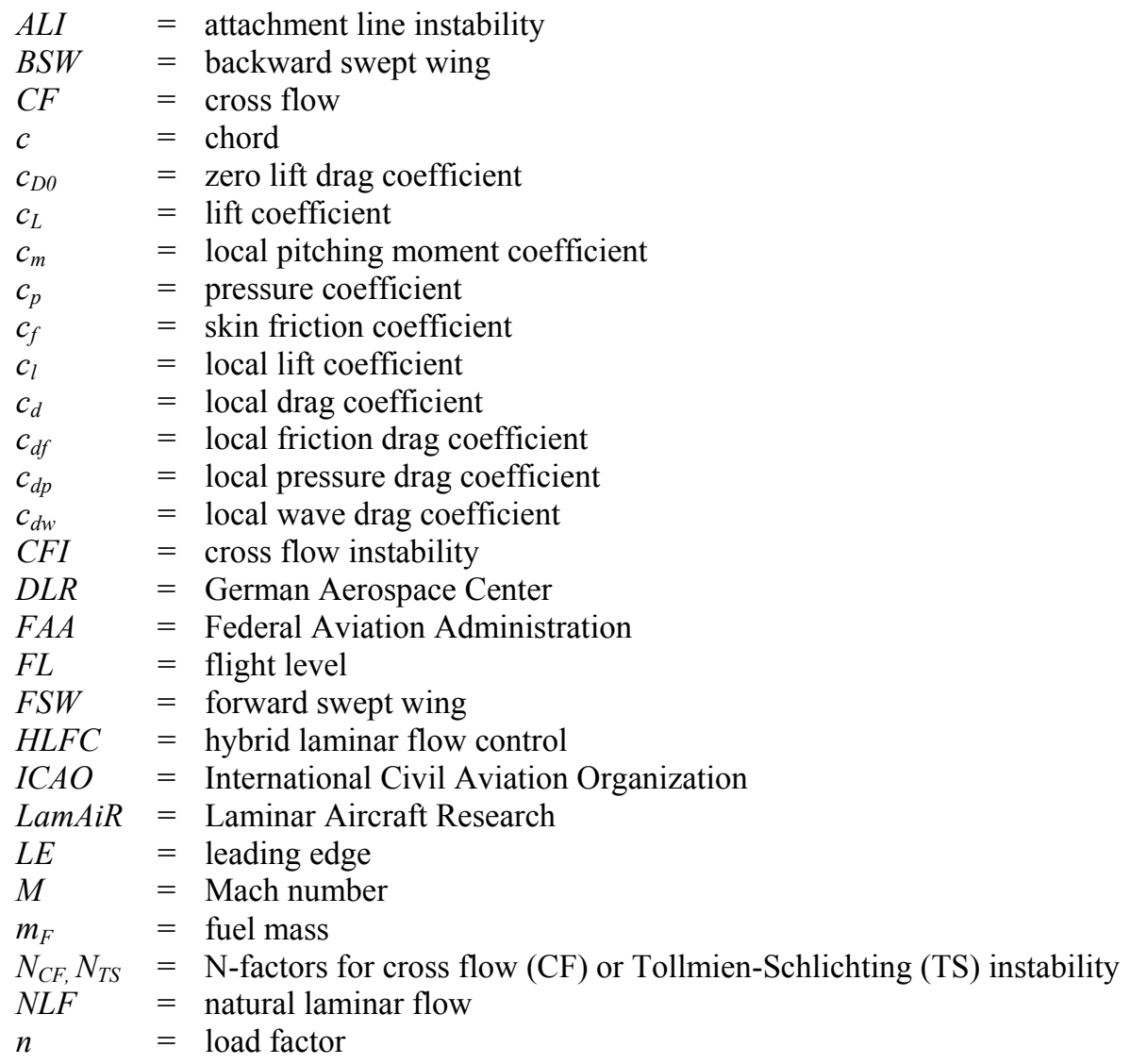

\footnotetext{
${ }^{1}$ Research Engineer, DLR Institute of Aerodynamics and Flow Technology, Lilienthalplatz 7, 38108 Braunschweig, email: martin.kruse@dlr.de, Phone:+49 531295 2960, Fax:+49 531295 2960,AIAA Member

${ }^{2}$ Research Engineer, DLR Institute of Aerodynamics and Flow Technology, Lilienthalplatz 7, 38108 Braunschweig, AIAA Member

${ }^{3}$ Research Engineer, DLR Institute of Institute of Composite Structures and Adaptive Systems, Lilienthalplatz 7, 38108 Braunschweig
} 


$\begin{array}{ll}\text { PAX } & =\text { passengers } \\ \text { PrADO } & =\text { Preliminary Aircraft Design and Optimisation - Program } \\ \operatorname{Re} & =\text { Reynolds number } \\ S & =\text { wing area } \\ \mathrm{S} & =\text { semi span } \\ T S I & =\text { Tollmien-Schlichting Instability } \\ T S F C & =\text { thrust specific fuel consumption } \\ t / c & =\text { airfoil thickness ratio } \\ V & =\text { flight velocity } \\ x, y, z & =\text { aircraft fixed cartesian coordinates } \\ x_{T} & =\text { x-position of laminar-turbulent transition } \\ \alpha & =\text { angle of attack } \\ \gamma & =\text { circulation } \\ \eta & =\text { normalized spanwise coordinate } \\ \lambda & =\text { taper ratio } \\ \varphi & =\text { sweep angle }\end{array}$

\section{Introduction}

$\mathrm{I}$ $\mathrm{n}$ response to increasing oil prices, airlines' fuel cost share has approximately doubled over the last decade. The continuation of this trend (Fig. 1) is expected, given the world's growing energy consumption and limited resources. This makes the development of more environmentally friendly, fuel efficient transport aircraft today's major challenge to the aircraft industry and research.

Numerous design and operational parameters affect the fuel burn of transport aircraft. Nicolai ${ }^{3}$ identified improvements to thrust specific fuel consumption (TSFC) and zero lift drag $\left(\mathrm{c}_{\mathrm{D} 0}\right)$ as those with the highest leverage to reduce fuel consumption. With respect to zero lift drag, the application of laminar flow technology would allow for significant improvements in viscous drag as the dominant contributor to $\mathrm{c}_{\mathrm{D} 0}$. At flight Reynolds numbers typically above $\mathrm{Re}=20$ millions, the skin friction coefficient of laminar flow is reduced by an order of magnitude compared to turbulent flow. Estimating the potential benefit of skin friction reduction by laminar flow technology for a typical jet airliner, a reduction of total drag by $10 \%-12 \%$ is predicted for an extent of laminar flow over $50 \%$ of the wing surface ${ }^{4}$.

In fact controlling the stability of the boundary layer of a swept wing at high chord Reynolds numbers is a difficult task. Unlike for unswept wings, where transition to turbulence is caused by the growth of Tollmien-Schlichting-instabilities ${ }^{5,6}$ alone, the swept wing's boundary layer is subject to cross-flowinstability (CFI) and attachment-line-instability (ALI) as well. Passive control of those combined instabilities by contour shaping of the airfoils is only possible up to moderate sweep angles and Reynolds numbers. Limits for natural laminar flow (NLF) are given by Schrauf ${ }^{7}$ as a function of leading edge sweep angle and

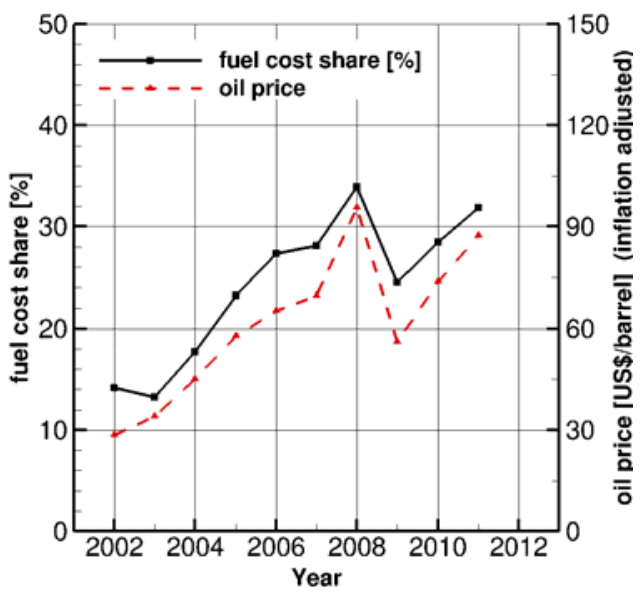

Figure 1. Development of crude oil price ${ }^{1}$ and fuel cost share w.r.t airline total costs ${ }^{2}$ chord Reynolds number.

For today's transonic transport aircraft with leading edge sweep angles of at least $25^{\circ}$, transition to turbulence is located at or close to the wing's leading edge, due to strong amplification of attachment-line instabilities or crossflow instabilities at flight Reynolds numbers. For such configurations, the only way to delay transition is the application of active boundary layer control methods.

Here, suction systems are the most common approach to stabilize laminar flow. Although hybrid laminar flow systems (HLFC), combining local suction and shaping, have proven their effectiveness in several flight test campaigns ${ }^{8,9,10}$, this technology is not available to the commercial aircraft market until now. Possible reasons for this non-application are seen in disadvantages from increased system complexity, additional power consumption and weight as well as operational aspects. 
With respect to short and medium range aircraft, current research on low-drag laminar flow wings seems to focus on NLF designs with significantly reduced sweep ${ }^{11}$ or even unswept wings ${ }^{12}$. The penalty of reducing wing sweep indeed is a reduced design cruise Mach number, in order to avoid excessive wave drag for those configurations. From the Breguet equation ${ }^{13}$, the aerodynamic figure of merit is known as the product of velocity and lift-to-drag-ratio for jet-powered cruise flight. Therefore some of the potential benefit due to drag reduction is lost when cruise velocity has to be reduced. The necessary trade-off involves many factors, mainly from mission requirements and flight operations that are not covered by the Breguet equation alone.

As outlined by Redeker and Wichmann ${ }^{14}$, forward swept, tapered wings (FSW) are found more suited for the design of transonic NLF configurations. For such a configuration, the geometrical leading edge sweep angle is reduced to values that allow for a passive control of CFI and ALI, while the absolute value of the shock sweep angle can be kept equivalent to a respective backward swept wing (BSW). Fig. 2 illustrates these changes to local sweep angles, assuming the shock position at $50 \%$ local chord for both planforms. Another important finding for the FSW is the reduction of the effective sweep angle near the leading edge due to 3D boundary layer displacement by the body and the wing itself. By this, the amplification of cross-flow related instabilities is further reduced. Finally, transition due to boundary layer contamination from the turbulent fuselage is an issue for the backward swept wing which does not exist for the forward swept wing.

The primary disadvantage of the forward swept wing is its inherent tendency for torsional aeroelastic divergence. For a conventional metallic wing structure, suppression of FSW's divergence problem requires structural reinforcements, leading to a significantly increased structural weight. Making use of anisotropic materials (e.g. CFRP) allows for an aeroelastic

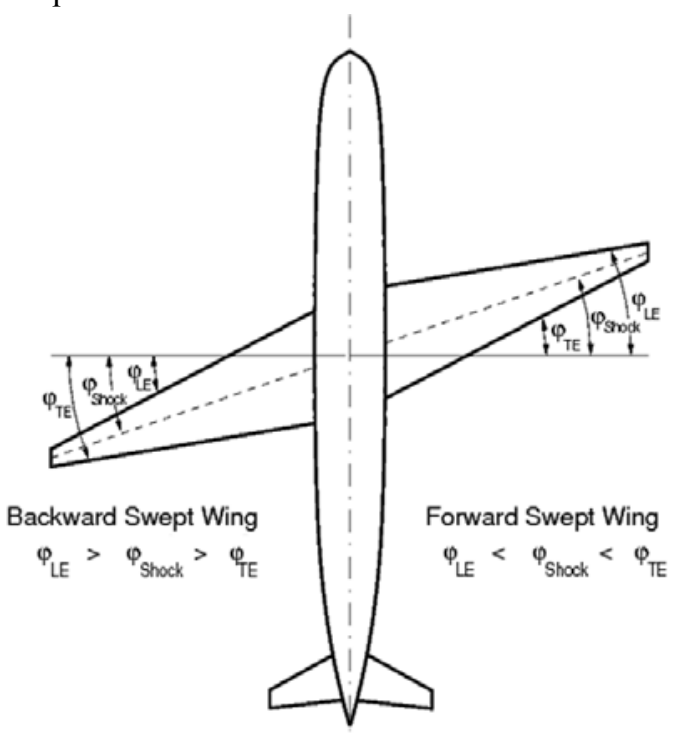

Figure 2. Sketch of tapered wing sweep angles for backward and forward swept configurations

tailoring of the wing against divergence ${ }^{15}$. In this case, the weight penalty for the forward swept wing is very moderate $^{16}$. The Grumman X-29 experimental fighter aircraft is an outstanding example of overcoming FSW's divergence problems by aeroelastic tailoring using anisotropic materials ${ }^{15,17}$.

Aware of the difficulties and encouraged by the theoretically achievable viscous drag reduction, DLR started investigating the potential of a forward swept NLF transport aircraft within the framework of DLR's LamAiR (Laminar Aircraft Research) project. The aim of the project is to investigate the feasibility of the concept of a forward swept wing aircraft, enabling for natural laminar flow over a wide extent of the wing at a design cruise Mach number of 0.78 . A target of $12 \%$ total drag reduction is set. To ensure comparability of the design study, top level aircraft requirements are chosen corresponding to those of an Airbus A320-200.

For the development of an aircraft configuration with NLF forward swept wings and the assessment of the overall performance data, preliminary design methods are employed. High fidelity methods are used for detailed aero-structural NLF wing design and performance predictions.

This paper gives a review of the preliminary aircraft design including several configuration studies, wing section design, aero-structural wing layout and provides an assessment of cruise flight performance by high fidelity methods. With respect to aircraft performance, results and assumptions made by preliminary aircraft design methods are compared to high fidelity results at cruise flight conditions. 


\section{Preliminary Aircraft Design and Configuration Studies}

\section{A. Top level aircraft requirements}

As stated before, the main goal of the LamAiR project is the design of a short and medium range transport aircraft featuring a forward swept NLF wing. For the initial sizing of such an aircraft, top level aircraft requirements have been defined that are equivalent to those of the Airbus A320-200 $0^{18,19}$. Table 1 gives an overview on the top level aircraft requirements and in Fig. 3 the related payload-range diagram is presented.

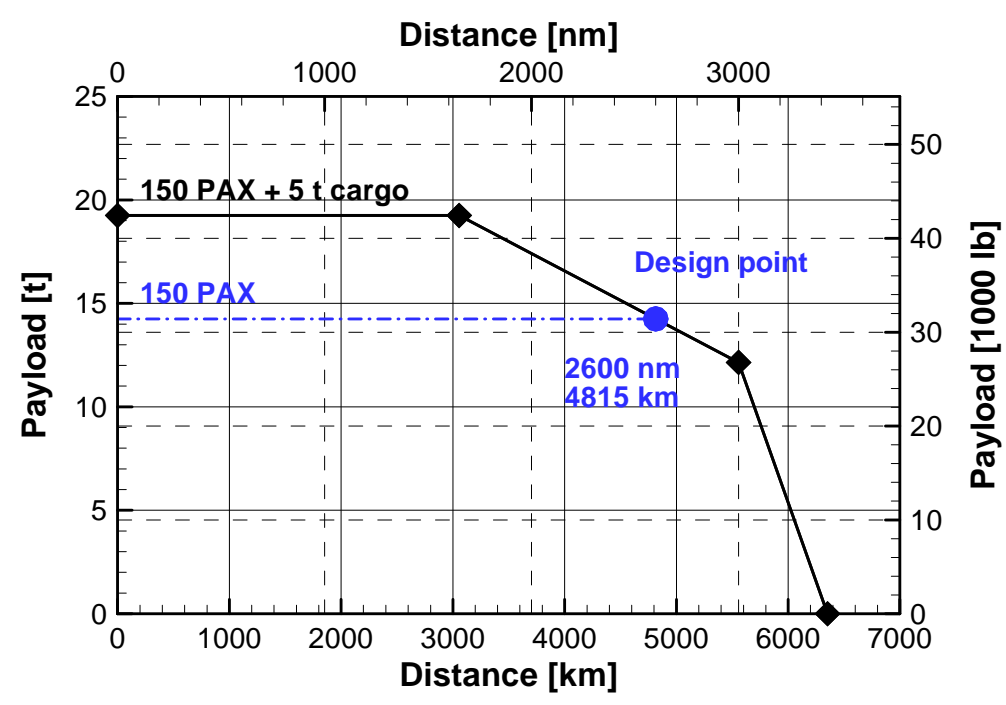

To guarantee the conformity with the airport infrastructure all considered aircraft configurations have to be inside the boundaries of the FAA Airplane Design Group III and the ICAO Aeroplane Design Code C. Hence the wingspan is limited to $36 \mathrm{~m}$ and the outer main gear wheel base must be not less than $6 \mathrm{~m}$. For the design of the natural laminar wing the design Mach number of 0.78 is the most challenging issue. Take-off and landing performance are not handled as hard requirements in the preliminary design context to get the benefits of a smaller engine for the regarded low drag aircrafts with NLF wings. All configurations are equipped with a turbofan engine in the CFM56 class.

Figure 3. Payload-range diagram used in the LamAiR-project.

\begin{tabular}{lcccccc}
\hline \multicolumn{1}{c}{ Conformity } & $\begin{array}{c}\text { Design } \\
\text { Mach No. }\end{array}$ & $\begin{array}{c}\text { Design } \\
\text { range }\end{array}$ & Payload & $\begin{array}{c}\text { Take-off } \\
\text { field length }\end{array}$ & $\begin{array}{c}\text { Landing } \\
\text { field length }\end{array}$ & Propulsion \\
\hline FAA Group III & 0.78 & $4815 \mathrm{~km}$ & $150 \mathrm{PAX}$ & $\approx 1900 \mathrm{~m}$ & $\approx 1500 \mathrm{~m}$ & $\begin{array}{c}\text { CFM56 class } \\
\text { turbofan }\end{array}$ \\
ICAO Code C & $(0.76-0.80)$ & & $5 \mathrm{t}$ cargo & & & \\
\hline
\end{tabular}

Table 1. Top level aircraft requirements used in the LamAiR-project.

\section{B. Used Models and Programs}

The investigations of the considered aircraft configurations on full aircraft level were performed with the PrADO $^{20,21,22}$ (Preliminary Aircraft Design and Optimization) program. This program has been developed by Technische Universität Braunschweig. It is based on a multi-lifting line method for aerodynamics, beam models for wing and fuselage structural sizing, a thermodynamic cycle engine model for propulsion and simple models for weight estimations and flight dynamics.

On input, the user prescribes a set of top level aircraft requirements, the basic geometry and the cabin layout of the aircraft. Based on the different models, PrADO then sizes all components of the aircraft and outputs a complete set of technical data as well as an estimate on all important performance parameters.

The structure of the PrADO program is capable of also treating unconventional aircraft configurations ${ }^{21,22}$, provided the database for the models is adapted to the problem. Since no such database existed for the forward swept NLF wing, the aerodynamic and structural model of PrADO has been updated in a fist step. 


\section{Model for the Profile Drag of the Natural Laminar Forward Swept Wing}

The calculation of the zero lift drag has been modified in the PrADO program to account for the natural laminar flow wing. The implemented model uses a flat-plate analogy for friction drag and considers laminar-turbulent transition with a weighted equivalent skin-friction coefficient published from Raymer $^{23}$ :

Equation 1

$$
C_{f e}(\eta)=\underbrace{F F_{l a} \frac{1.328}{\operatorname{Re}^{1 / 2}(\eta)} \frac{x_{T}}{c}(\eta)}_{\text {la } \min a r}+\underbrace{F F_{t u} \frac{0.074}{\operatorname{Re}^{1 / 5}(\eta)}\left(1-\frac{x_{T}}{c}(\eta)\right)}_{\text {turbulent }}
$$

The equivalent skin friction coefficient considers the pressure drag from viscous effects with the "form factors" $\mathrm{FF}_{\mathrm{la}}$ for laminar boundary layers and $\mathrm{FF}_{\mathrm{tu}}$ for turbulent boundary layers. The zero lift drag of the wing is then estimated with a prescribed laminar-turbulent transition dependent on the Reynolds number and the integration of Equation 1 in spanwise direction.

For the preliminary aircraft design in the LamAiR-project the laminar-turbulent transition from Fig. 4 has been used. In the Reynolds number range up to 25 million a 55\% extension of laminar flow has been assumed. Between

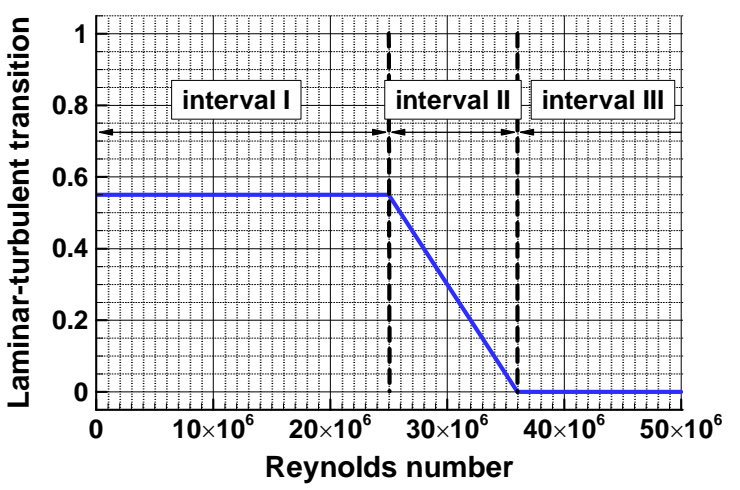

Figure 4. Prescribed laminar-turbulent transition based on NLF airfoil design.

Reynolds numbers of 25 million and 36million a linear reduction is used in the model. These prescribed values are based on the results of the natural laminar airfoil design for the selected design Mach number, the selected leading edge sweep, local lift coefficients and local airfoil thicknesses.

With this approach the complex influences of the local lift coefficient $c_{l}(\eta)$ and the local airfoil thickness $(t / c)(\eta)$ to the laminar-turbulent transition are indirectly included in the model. Furthermore no differentiation of the upper and lower side with regard to the laminar-turbulent transition is considered. So the equivalent skin-friction coefficient $\mathrm{C}_{\mathrm{fe}}(\eta)$ has to be perceived as the average value of the lower and upper surface.

The form factors for laminar and turbulent boundary layers were derived from high fidelity airfoil analysis with a variation of forced laminar-turbulent transition. These investigations were done for a typical turbulent airfoil and a designed NLF airfoil. The selected Mach number was

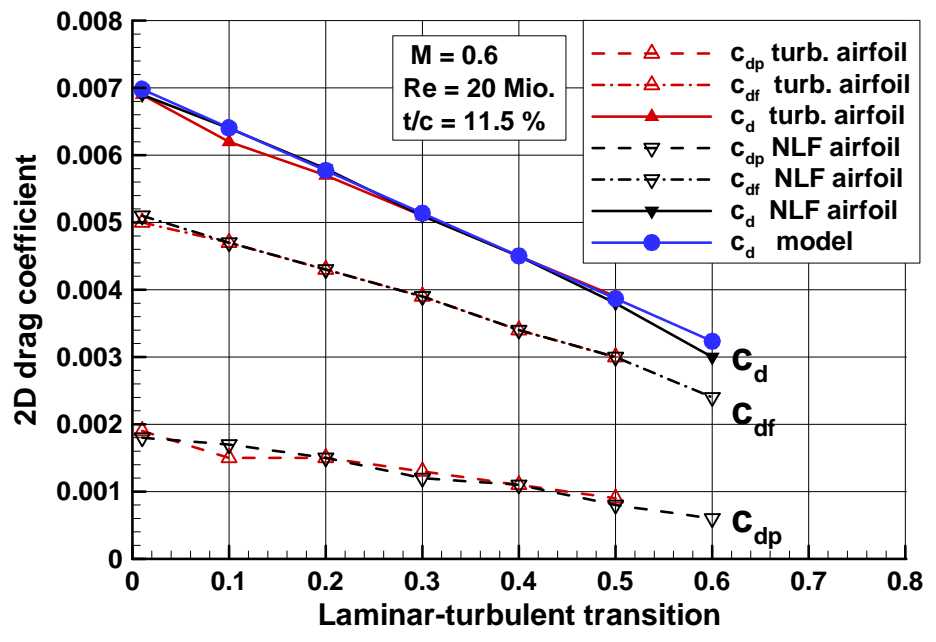

Figure 5. Validation of the "form factors" with forced transition for turbulent and NLF airfoil analysis. below the critical Mach number of these airfoils to avoid any wave drag influence. In Fig. 5 the results of the model validation are presented. With the selected values for the "form factors" of $\mathrm{FF}_{\mathrm{la}}=1.15$ for laminar boundary layers and $\mathrm{FF}_{\mathrm{tu}}=1.35$ for turbulent boundary layers a good agreement with the airfoil analysis was achieved.

\section{Model for the high-lift system}

The requirements for the take-off and landing performance and the effectiveness of the high-lift system determine the wing area. For suitable cruise flight performance and low wing mass the wing loading has to be in the order of $600 \mathrm{~kg} / \mathrm{m}^{2}$ for transport aircraft ${ }^{23}$. This is associated with a maximum lift coefficient in landing configuration in the order of $c_{\mathrm{Lmax}}=3.0$ for a 
short to medium range transport aircraft ${ }^{24}$ in the Airbus A320 class. To reach such $c_{L}$ values, a combination of leading and trailing edge high-lift devices is used by today's transport aircraft.

The surface requirements for laminar flow don't allow gaps, steps or slots. Only leading edge devices which are compatible with these surface requirements could be used for the NLF wings in the LamAiR-project. Such a device could be made from smart material that allows for a movable droop nose as recently proposed by the DLR Institute of Composite Structures ${ }^{25,26,27}$. The second major issue is the influence of the highly swept trailing edge on the highlift capability of the forward swept NLF wing.

In PrADO, a multi-lifting line method is used with a prescribed maximum local lift coefficient to predict the maximum lift coefficient of the wing in cruise flight configuration. In Table 2 the selected maximum local lift coefficients without high-lift device deflections are given for turbulent and NLF airfoils. The value for the NLF airfoils is lower to consider the negative influence of the lower leading edge radius to the maximum lift coefficient.

\begin{tabular}{lll}
\hline \multicolumn{1}{c}{ Aircraft } & \multicolumn{1}{c}{ Airfoils } & $\begin{array}{c}\text { Maximum airfoil lift coefficient } \\
\text { without high-lift device deflections }\end{array}$ \\
\hline Reference aircraft & Full turbulent & $\mathrm{c}_{1, \text { max,cean }}=1.6$ \\
LamAiR configurations & Natural laminar flow (NLF) & $\mathrm{c}_{1, \text { max,clean }}=1.4$ \\
\hline
\end{tabular}

Table 2. Selected maximum airfoil lift coefficients without high-lift device deflections.

With the associated spanwise distribution of the local lift coefficient, modifications of the local lift coefficients for the given high lift devices are considered. The selected values for the local lift coefficient modifications are based on data from Roskam ${ }^{28}$, Sanders ${ }^{29}$, and Kintscher et al. ${ }^{27}$ and listed in Table 3. For the transformation between 2D and 3D values of the local lift, modifications the sweep angle of the hinge line of the corresponding high-lift device are used, as recommended by Raymer ${ }^{23}$.

\begin{tabular}{llllll}
\hline \multicolumn{1}{c}{ Aircraft } & High-lift device & $\begin{array}{c}\text { Maximum } \\
\text { deflection } \\
\delta_{F, \text { max }}\end{array}$ & $\begin{array}{c}\text { Modification of } \\
\text { maximum 2D } \\
\text { lift coefficient } \\
\Delta c_{\text {l,max }}\end{array}$ & $\begin{array}{c}\text { Modification } \\
\text { of 2D drag } \\
\text { coefficient } \\
\Delta c_{d}\end{array}$ & $\begin{array}{c}\text { Modification of } \\
\text { 2D pitching } \\
\text { moment } \\
\text { coefficient } \Delta c_{m}\end{array}$ \\
\hline Reference aircraft & Slat & $27^{\circ}$ & 0.9 & 0.0 & 0.11 \\
LamAiR configurations & $\begin{array}{l}\text { Droop nose } \\
\text { ("smart leading edge") }\end{array}$ & $18^{\circ}$ & 0.5 & 0.0 & -0.04 \\
Reference aircraft & Fowler flap & $35^{\circ}$ & 1.5 & 0.1 & -0.4 \\
LamAiR configurations & Large Fowler flap & $35^{\circ}$ & 1.6 & 0.11 & -0.43 \\
\hline
\end{tabular}

Table 3. Selected modifications of the 2D aerodynamic coefficients for several high-lift devices.

\section{Model for the Sizing and Mass Estimation of the CFRP Wing}

In the preliminary aircraft design with PrADO, the wing structure is modeled with a beam model. The structural sizing of the wing is carried out for 10 load cases. The load cases consider critical points in the V-n diagram (Pratt chart), variations of payload, several fuel masses, impact of touch down and ground loads. This wing sizing procedure is validated for conventional wing design in aluminum.

For the forward swept NLF wing of the LamAiR configurations carbon fiber reinforced plastics (CFRP) are employed in order to tailor the deformation of the wing box. In the preliminary aircraft design the static aeroelastic characteristics of the flexible wing has been neglected. This simplification correlates with the design goal of the forward swept NLF wing to decouple the bending and twist.

In comparison to a conventional metal structure the usage of advanced composites like CFRP leads to a significant mass reduction of the wing structure. For this reason, a wing mass reduction of $10 \%$ has been assumed for the CFRP wing structure in comparison to the design in aluminum. This selected value is more conservative than the estimated $15 \%$ mass reduction for wing structures published by Raymer ${ }^{23}$. 


\section{Configuration Studies}

With the presented models for aerodynamics and structural mass estimation the sizing of the LamAiR aircraft has been done by performing systematic configuration variations. All considered aircraft configurations have been sized for the given top level aircraft requirements from Fig. 3 and Table 1.

In order to guarantee comparability with the selected reference aircraft, not only the top level aircraft requirements were retained for the LamAiR configuration variations. As an additional constraint it has been demanded that stability and control for longitudinal and lateral motion are also equivalent. Furthermore the engine has been scaled with the required amount of thrust for several critical flight conditions. This is a common approach in preliminary aircraft design and well known as "rubber engine".

\section{Conventional Reference Aircraft}

The reference aircraft configuration is a single aisle passenger aircraft of the Airbus A320 class with a capacity of 150 passengers. The PrADO model is shown in Fig. 6 and represents a redesign of the Airbus A320-200 on the

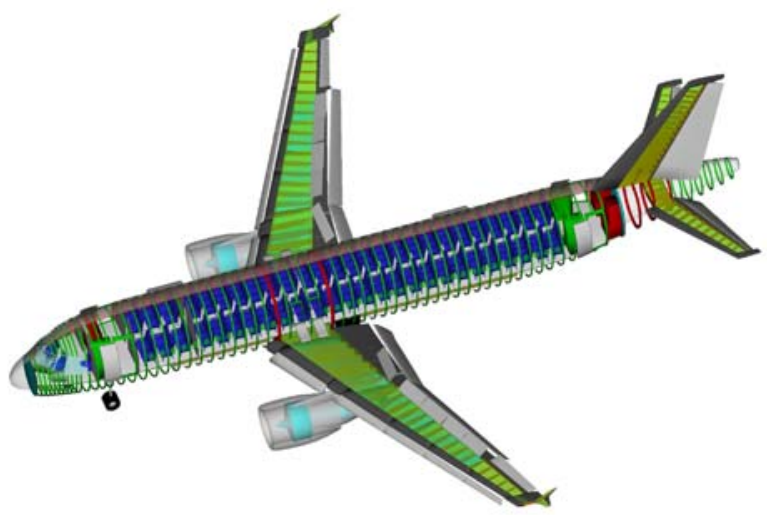

Figure 6. Conventional aircraft configuration. basis of published data. The low wing arrangement with conventional tailplane and two under-wing mounted engines is state of the art for this aircraft category. The wing, the main landing gear and the engines are placed near the center of gravity. This results in a good balanced configuration in terms of wing and fuselage loads and a large moment arm for the tailplane. Furthermore the backward swept wing offers good aerodynamic performances in the transonic cruise flight with turbulent boundary layers and under take-off and landing conditions with the effective high-lift system.

The main disadvantages are the limitation of the engine size in the under-wing position, relatively long landing gear and a separated cargo compartment.

Some fundamental data and PrADO results are given in Table 4 for the conventional reference aircraft.

\section{Configuration with Rear Mounted Engines and T-tail}

The configuration with rear mounted engines and T-tail has been developed from the reference aircraft and is shown in Fig. 7. The wing geometry is identical to the reference aircraft and has been rearranged to maintain similar stability and control for longitudinal and lateral motion. The rear fuselage geometry has been modified for the

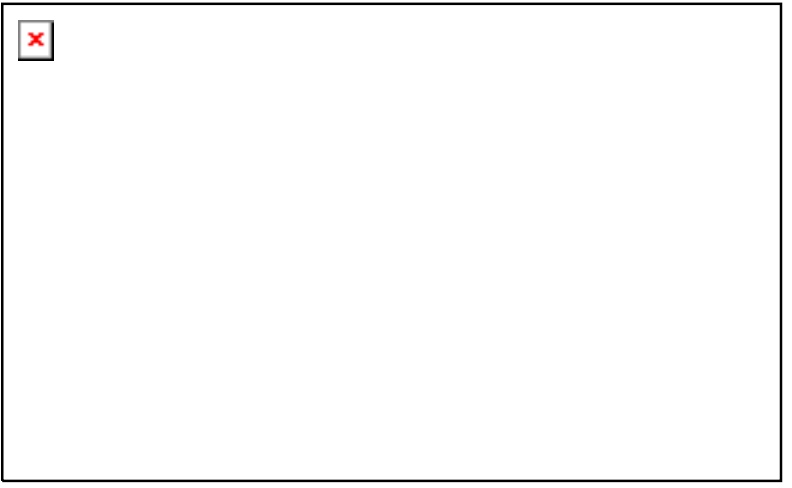

Figure 7. Configuration with rear mounted engines and T-tail. engine installation and for the newly designed and sized T-tail. In addition a shorter landing gear with lower mass has been used.

The preliminary aircraft sizing with PrADO predicts an increased maximum take-off mass of $2 \%$ in comparison to the reference aircraft. The reasons are the increased fuselage loads due to the changes in the mass distribution with the aft fuselage mounted engines and the absence of the engine under the wing to reduce the wing loads. The increased mass results in an increased fuel consumption of $3 \%$ for the design mission. It should be noted, that this configuration offers a better potential for future engine concepts (ultra high bypass ratio turbofan, open rotor) with larger dimensions. 


\section{Conventional Aircraft Configuration with CFRP Wing and Increased Span}

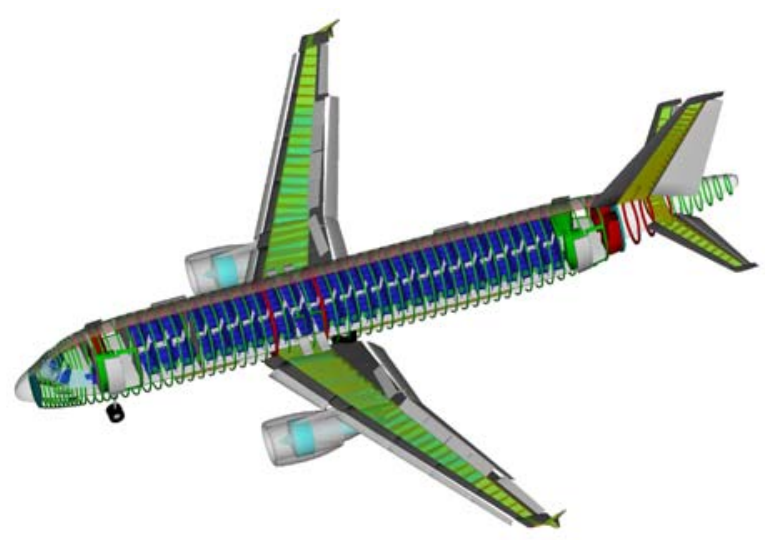

Figure 8. Conventional aircraft configuration with CFRP wing and increased span.
The LamAiR configurations require a structural wing design in CFRP with an increased span to get all aerodynamic benefits of the forward swept NLF wing. For the assessment of the forward swept NLF wing concept a further development of the conventional aircraft configuration has to be considered additionally. For this reason a conventional aircraft configuration with a CFRP wing, increased span and improvements in turbulent transonic airfoil design has been investigated. The PrADO model of this configuration is shown in Fig. 8. The selected design point with a lift coefficient of $\mathrm{c}_{\mathrm{L}}=0.57$ results in a reduction of fuel consumption by $7 \%$ in comparison to the reference aircraft. Some fundamental data and PrADO results are given in Table 4 for the conventional aircraft configuration with CFRP wing and increased span.

\section{LamAiR Configurations with NLF Forward Swept Wings}

The LamAiR configurations combine the aerodynamic benefits of the NLF wing design with an increased wing span and bases on the configuration with rear mounted engines and T-tail. The impact of an engine installation change has been discussed for the backward swept reference aircraft. For the forward swept wing aircraft, studies on engine installation revealed a potential mass increase by $3 \%$ when a rear-mounted engine is used instead of an under-wing placement.

However, it was decided that the principal LamAiR configuration will use rear-mounted engines and a T-tail for two reasons: Firstly, the wing will be aerodynamically clean. With an engine mounted below the wing, it is very likely that, due to interference effects, pressure distributions of wing sections in the vicinity of engine and pylon can hardly be designed to allow for a laminar boundary layer. Secondly, it is expected that future engines will feature higher bypass ratios leading to larger engine diameters. The retrofit of such an engine at a rear fuselage position should be much easier compared to an installation under the wing because it is not necessary to modify the main landing gear. In addition, the long undisturbed fuselage section in front of the wing is suited for the usage of carbon fiber reinforced plastic materials to reduce the fuselage mass.

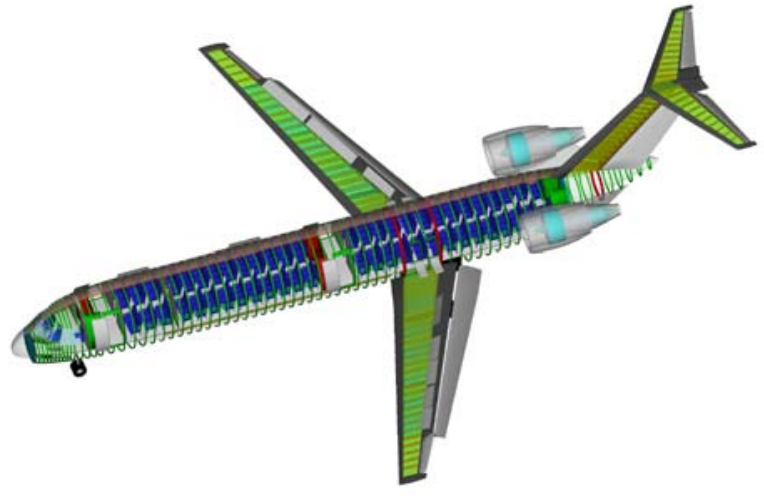

Figure 9. LamAiR I configuration with forward swept NLF wing $\left(S=119.5 \mathrm{~m}^{2}\right)$ without $\mathrm{LE}$ high-lift device.
The starting point of the LamAiR-project was the LamAiR I configuration with a wing area in the order of the reference aircraft, an increased wingspan of $35.5 \mathrm{~m}$ and a leading edge sweep of $\varphi_{\mathrm{LE}}=-17^{\circ}$. The dimensions of this forward swept wing have been selected for the maximum extent of natural laminar flow. No leading edge high-lift device has been provided to be compatible with surface requirements for laminar flow. In Fig. 9 the PrADO model of the LamAiR I configuration is shown. The performance data calculated with PrADO shows a $17 \%$ higher lift-to-drag ratio under cruise flight condition, an increased maximum take-off mass in the order of $2 \%$ and a $9 \%$ reduced fuel consumption in comparison to the reference aircraft. But the estimated maximum lift coefficient in landing configuration is $18 \%$ below the value of the reference aircraft. So the take-off and landing performance results in a $42 \%$ longer take-off field length, a $14 \%$ increased approach speed and a $27 \%$ longer landing field length. These low speed performances lead to unacceptable operational limitations of the LamAiR I configuration. 
To fulfill the top level aircraft requirements in terms of the take-off and landing performances from Table 1 two further configurations has been investigated. The first configuration consists of a forward swept wing with an

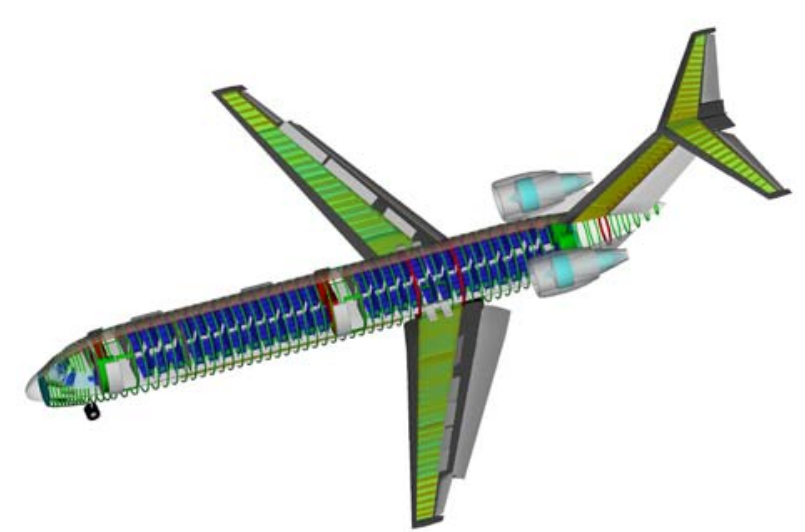

Figure 10. LamAiR II configuration with forward swept NLF wing $\left(S=145 \mathrm{~m}^{2}\right)$ without $\mathrm{LE}$ high-lift device. increased wing area and span. The PrADO model of this LamAiR II configuration is shown in Fig. 10. To be in compliance with the ICAO Code $\mathrm{C}$ and the FAA Group III the wingspan has been limited to $35.8 \mathrm{~m}$. The growth in the wing area to $S=145 \mathrm{~m}^{2}$ results in an increased maximum take-off mass in the order of $4 \%$ in comparison to the reference aircraft. The aerodynamic cruise performance is with a benefit in the lift-to-drag ratio of $16 \%$ compared to the reference aircraft in the same order of the LamAiR I configuration. This results in a reduced fuel consumption of $6 \%$ for the LamAiR II configuration in comparison to the reference aircraft. Furthermore the estimated take-off and landing performance has been improved, but an 18\% increased take-off field length in comparison to the reference aircraft is still unacceptable.

The aim of the second concept is to improve the takeoff and landing performances while maintaining the advantages of the forward swept NLF wing in terms of fuel saving. Under the assumption that a leading edge device compatible with surface requirements for laminar flow will be available the LamAiR III configuration has been investigated. To match the targeted landing field length from

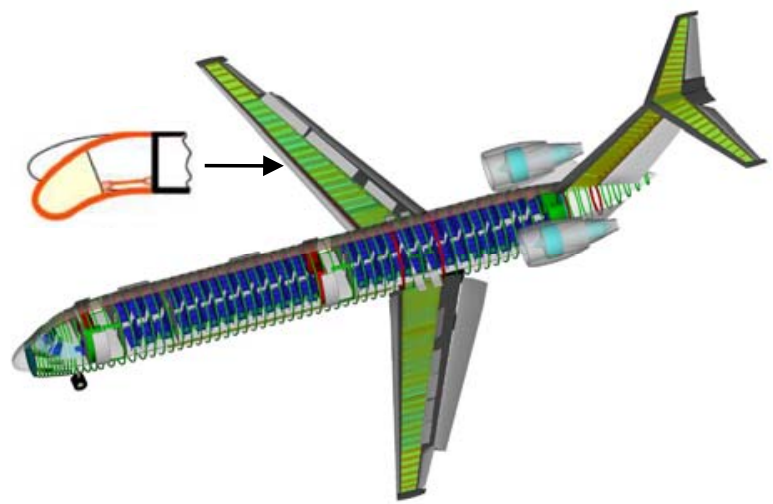

Figure 11. LamAiR III configuration with forward swept $\mathrm{NLF}$ wing $\left(\mathrm{S}=132 \mathrm{~m}^{2}\right)$ with smart droop nose LE high-lift device.

Table 1, a smart droop nose leading edge device in combination with a large single slotted Fowler flap has been considered. The PrADO model of the LamAiR III configuration and schematic drawing of the smart droop nose from the European project SADE ${ }^{25,26,27}$ is shown in Fig. 11. The drawbacks in the effectiveness of the selected high-lift system are compensated by increasing the selected wing area to $S=132 \mathrm{~m}^{2}$. Wing planform variations of the LamAiR III configuration show a reduction in fuel consumption with increasing span. Therefore a value of $35.8 \mathrm{~m}$ for the wingspan has been selected to fulfill the top level aircraft requirements in terms of airport conformity.

In Fig. 12 variations of the design lift coefficient for cruise flight conditions are shown. For each lift coefficient in the graph a complete PrADO computation has been performed. It can be seen that the fuel consumption (given here in liter per 100km range and $100 \mathrm{~kg}$ payload) for the design mission (see Fig. 3) has a minimum at about $\mathrm{c}_{\mathrm{L}}=0.56$. However, this graph has been generated under the assumption that the airfoil characteristics can be retained when changing the design $c_{L}$. But as the airfoil investigations revealed, especially drag rise will become a problem at such high $c_{\mathrm{L}}$ levels. Therefore, the target lift coefficient of the LamAiR III configuration has been chosen to be $\mathrm{c}_{\mathrm{L}}=0.5$.

Assessment of the performance data calculated with PrADO for all three configurations revealed that the LamAiR III configuration has the highest potential to deliver the desired fuel burn reductions and comply at the same time with the top level aircraft requirements. So the LamAiR III configuration has been selected as the basis for further investigations with respect to detailed aerodynamic and structural wing design.

In Table 4 fundamental data and results of the reference aircraft, the conventional aircraft configuration with CFRP wing and increased span and the LamAiR III configuration are presented to summarize the preliminary aircraft design and configuration studies. The LamAiR III configuration shows a 9\% reduction in fuel consumption 

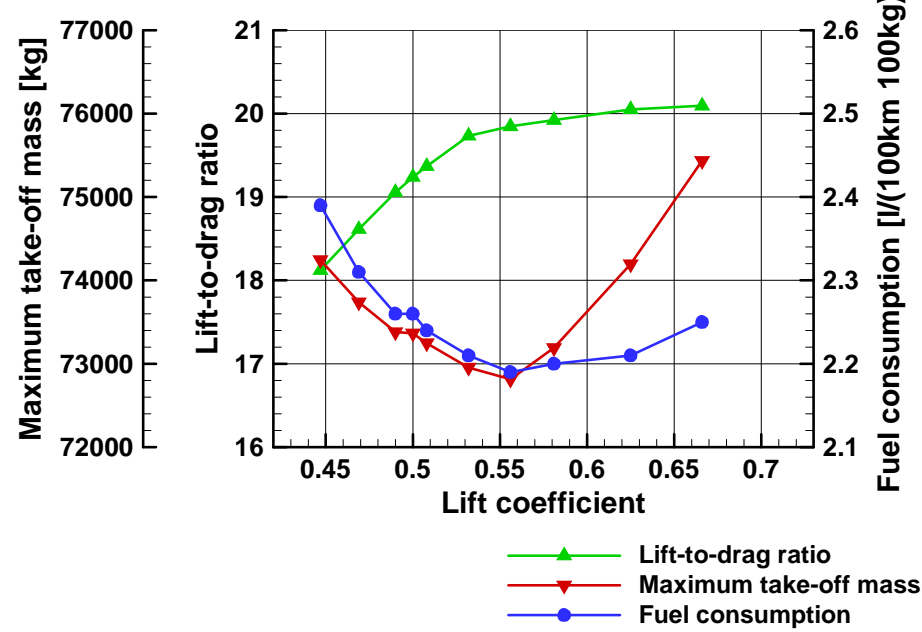

for the design mission in comparison to the conventional reference aircraft. This result includes a drawback of $3 \%$ in terms of fuel consumption due the engine installation position. For the conventional aircraft configuration with CFRP wing and increased span a 7\% reduction of fuel consumption has been calculated. So the forward swept wing NLF concept shows a superior potential of fuel saving for the design mission. Additionally for the rear mounted engine configurations a higher benefit from the integration of future engine concepts (ultra high bypass ratio turbofan, open rotor) with larger dimensions will be expected. It should be remarked that not all operational aspects of wings with laminar flow are considered in the presented studies.

Figure 12. Variation of lift coefficient of the LamAiR III configuration.

\begin{tabular}{|c|c|c|c|}
\hline Aircraft & Reference aircraft & $\begin{array}{c}\text { Conventional aircraft } \\
\text { with CFRP wing }\end{array}$ & $\begin{array}{c}\text { LamAiR III } \\
\text { configuration }\end{array}$ \\
\hline \multicolumn{4}{|l|}{ Wing } \\
\hline Wing area & $122.6 \mathrm{~m}^{2}$ & $122.6 \mathrm{~m}^{2}$ & $132.0 \mathrm{~m}^{2}$ \\
\hline Span & $34 \mathrm{~m}$ & $35.8 \mathrm{~m}$ & $35.8 \mathrm{~m}$ \\
\hline \multicolumn{4}{|l|}{ Aerodynamics } \\
\hline Maximum lift coefficient landing & 3.02 & 3.02 & 2.86 \\
\hline Initial cruise altitude & $10 \mathrm{~km}(32808 \mathrm{ft})$ & $11 \mathrm{~km}(36089 \mathrm{ft})$ & $10.5 \mathrm{~km}(34449 \mathrm{ft})$ \\
\hline Lift coefficient cruise & 0.50 & 0.57 & 0.50 \\
\hline Lift-to-drag ratio & 16.4 & 17.9 & 19.2 \\
\hline \multicolumn{4}{|l|}{ Masses } \\
\hline Operating empty mass & $41350 \mathrm{~kg}(91160 \mathrm{lb})$ & $41380 \mathrm{~kg}(91220 \mathrm{lb})$ & $43710 \mathrm{~kg}(96370 \mathrm{lb})$ \\
\hline Maximum take-off mass & $72550 \mathrm{~kg}(159950 \mathrm{lb})$ & $71430 \mathrm{~kg}(157480 \mathrm{lb})$ & $73360 \mathrm{~kg}(161740 \mathrm{lb})$ \\
\hline \multicolumn{4}{|l|}{ Performance } \\
\hline Take-off field length & $1750 \mathrm{~m}(5750 \mathrm{ft})$ & $1640 \mathrm{~m}(5380 \mathrm{ft})$ & $1900 \mathrm{~m}(6240 \mathrm{ft})$ \\
\hline Landing field length & $1560 \mathrm{~m}(5130 \mathrm{ft})$ & $1610 \mathrm{~m}(5280 \mathrm{ft})$ & $1560 \mathrm{~m}(5110 \mathrm{ft})$ \\
\hline Fuel consumption & $2.50 \mathrm{l} /(100 \mathrm{~km} 100 \mathrm{~kg})$ & $2.32 \mathrm{l} /(100 \mathrm{~km} 100 \mathrm{~kg})$ & $2.26 \mathrm{l} /(100 \mathrm{~km} 100 \mathrm{~kg})$ \\
\hline
\end{tabular}

Table 4. Fundamental data and results for the reference aircraft, the conventional aircraft with CFRP wing and the LamAiR III configuration with forward swept NLF wing. 


\section{Wing Section Design}

Airfoil data for preliminary design purposes are often taken from catalogues or handbooks. Commonly these data are of two-dimensional nature, i.e. they are gathered in wind-tunnel measurements on two-dimensional airfoil sections or, more often, originate from a two-dimensional CFD analysis. In order to incorporate the effect of wing sweep, simple transformations based on the cosine $\varphi$ - law for infinite swept wings are applied, where usually the sweep at the shock location is taken as the angle $\varphi$.

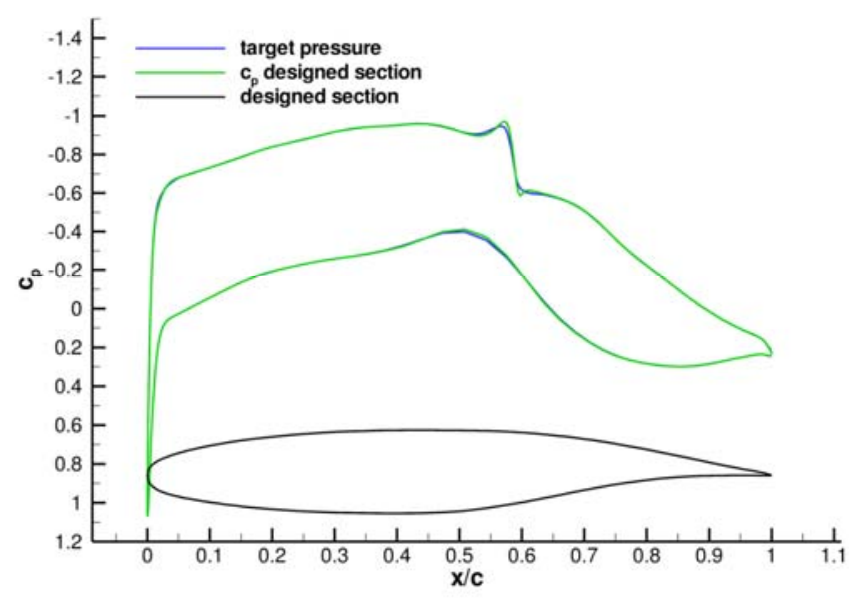

Figure 13. Result of airfoil design for forward swept NLF wing. Shown are pressure distribution and contour for a typical inboard section at design point $\mathrm{M}=\mathbf{0 . 7 8}, \mathrm{Re}_{\mathrm{c}} / \mathbf{1 0}^{6}=25, \mathrm{c}_{\mathrm{l}}=\mathbf{0 . 5 5}$

However, in case of a NLF forward swept wing application this approach appears to be inappropriate. As pointed out before, variation from low sweep angles at the leading edge to high sweep angles at the trailing edge due to taper has an impact on airfoil characteristics. Especially transition location with related friction drag and shock strength with related wave drag are affected. Therefore, within the LamAiR project, airfoil design and analysis are performed using a computational method that was recently developed by Streit. ${ }^{30}$ The method is based on sectional conical wings and allows the analysis and design of airfoil sections for swept and tapered wings with a computational effort that is only slightly higher than for a $2 \mathrm{D}$ computation. Of course the method is not fully $3 \mathrm{D}$ but because a sectional conical wing is treated it reflects more three-dimensional effects than a method for infinite swept wings. Therefore it is referred to as $2.75 \mathrm{D}$.

Using the $2.75 \mathrm{D}$ method, a set of airfoils was generated to build up a database for NLF forward swept wing application. The design requirements were:

- $\mathrm{M}=0.78$ at $\mathrm{Re}_{\mathrm{c}}=20-30$ million

- $\mathrm{c}_{1}=0.45-0.60$ and $\mathrm{c}_{\mathrm{m} 25}>-0.12$

- leading edge sweep $\varphi_{\mathrm{LE}}=-16^{\circ}--19^{\circ}$

- taper ratio $\lambda=0.30$

- thickness as high as possible for typical inboard sections

- laminar boundary layer on upper and lower side up to approx. $50 \%$ chord

Fig. 13 shows exemplarily a result of the design work for a typical inboard section of a conical wing with -17deg leading edge sweep. Design point here was $M=0.78$ and $\mathrm{Re}_{\mathrm{c}}=25$ million, the lift coefficient $\mathrm{c}_{1}=0.55$. With a target pressure distribution following the rules described in section II, a profile with a relative thickness of $t / c=0.13$ and a pitching moment coefficient of $\mathrm{c}_{\mathrm{m} 25}=-0.10$ was generated utilizing the inverse design capabilities of the 2.75D method.

After having checked that no ALT occurs (in this case: $\operatorname{Re}_{\theta}=74<100$ !), Transition prediction was performed on the basis of a two N-factor method. Employing the linear stability analysis code LILO developed by Schrauf ${ }^{31}$, Nfactor distributions for crossflow instabilities (treated as zero Hertz stationary waves) and Tollmien-Schlichting instabilities (treated as fixed frequency travelling waves that propagate in direction of the outer flow) are calculated.

The transition criterion is a combined $\mathrm{N}_{\mathrm{TS}}-\mathrm{N}_{\mathrm{CF}}$ criterion that was evaluated at DLR from the ATTAS flight tests ${ }^{32,33}$ performed in 1987. The critical $\mathrm{N}$-factors are $\mathrm{N}_{\mathrm{TS}}=11$ for Tollmien-Schlichting and $\mathrm{N}_{\mathrm{CF}}=10$ for crossflow instabilities. It should be noted that the flight tests also revealed nearly no interaction between TSI and CFI. 


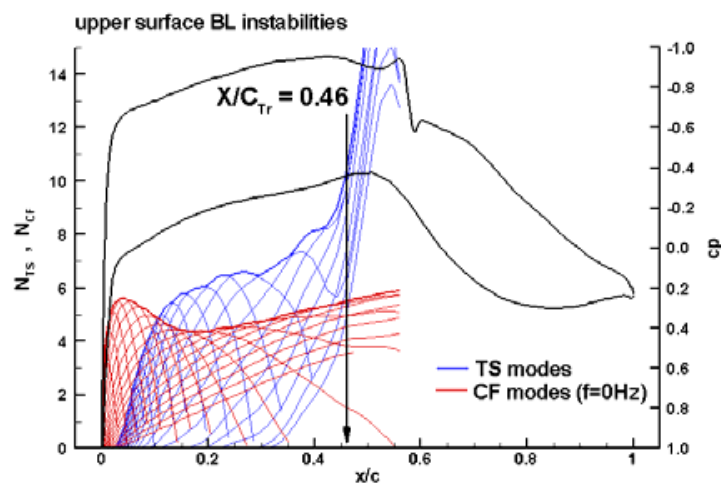

amplified frequency range TS modes: $7.8 \mathrm{kHz}-65.0 \mathrm{kHz}$ amplified stationary CF wavelengths: $2.2 \mathrm{E}-4 \mathrm{~m}-28 \mathrm{E}-4 \mathrm{~m}$

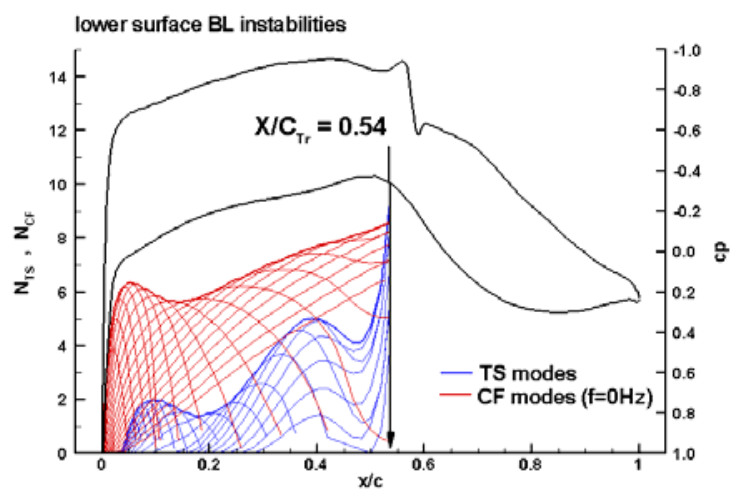

amplified frequency range TS modes: $7.9 \mathrm{kHz}-49.0 \mathrm{kHz}$ amplified stationary CF wavelengths: $2.5 \mathrm{E}-4 \mathrm{~m}-26 \mathrm{E}-4 \mathrm{~m}$

Figure 14. Transition prediction for upper and lower surface of typical inboard section at design point. Shown are pressure distribution and $\mathrm{N}$-factor distributions for TSI and CFI.

Fig. 14 shows the N-factor distributions for CFI and TSI on the upper (left) and the lower (right) side of the designed airfoil. According to the diagrams, transition occurs in both cases shortly after the pressure minimum is reached in a region with adverse pressure gradient, where amplitudes of Tollmien-Schlichting instabilities grow rapidly. Due to the low leading edge sweep of only $17^{\circ}$, crossflow instabilities constitute no serious problem and there is even a certain safety margin to the threshold of $\mathrm{N}_{\mathrm{CF}}=10$. It should be mentioned that on the upper surface transition was enforced to take place just ahead of the shock position in order to prevent laminar separation at the shock.

In Fig. 15 results of a drag analysis for the typical inboard airfoil section are presented. Shown are the variations of wave drag $\mathrm{c}_{\mathrm{dw}}$ and friction drag $\mathrm{c}_{\mathrm{df}}$ with Mach number for lift coefficients $\mathrm{c}_{\mathrm{l}}=0.45,0.5$ and 0.55 . As can be seen, the friction drag decreases with increasing Mach number because transition on the upper side of the profile moves further downstream.

The wave drag is in the order of $\mathrm{c}_{\mathrm{dw}}=3$ drag counts up to the design point at $\mathrm{M}=0.78$ but then increases rapidly. Nevertheless, on the upper branch of the LamAiR cruise range $(\mathrm{M}=0.80)$, i.e. in high-speed conditions, where lift requirements are lowered, the wave drag for lift coefficients $c_{1}=0.45$ and 0.5 still is acceptable. It should be noted that the inboard airfoil section, compared with those designed for span stations that are more outboard, is the thickest one. With respect to wave drag at high lift coefficients the inboard airfoil section therefore is the critical one. As previously mentioned, characteristics, i.e. performance as well as geometry data, were generated in the same way as described above for a complete set of airfoil sections and then used to update the aerodynamic modelling of the PrADO program
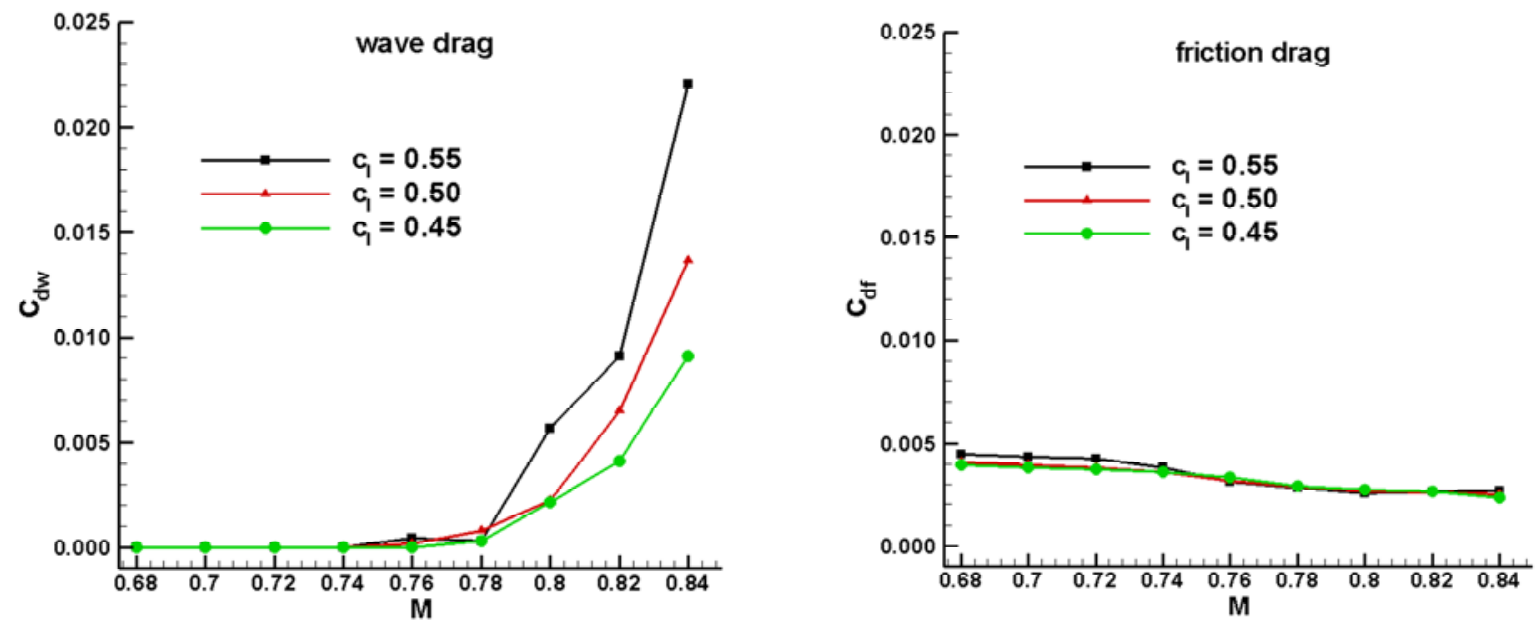

Figure 15. Development of wave and friction drag for typical inboard section with Mach number, $\operatorname{Re}_{\mathrm{c}}=\mathbf{2 5 E 6}$ 


\section{Aero-Structural Wing Design}

Due to the inherent tendency for torsional divergence, the design of a forward swept wing is a multidisciplinary challenge to aerodynamics and structural mechanics. In this section we summarize major considerations and key results of the aerodynamic design process, give an outline on fluid-structure coupled simulations and describe the aeroelastic tailoring of the structure mechanical model.

\section{A. Aerodynamic Design}

\section{Wing Planform and spanwise circulation}

Few published studies on the design of high aspect ratio wings exist. McGeer ${ }^{34}$ conducted a constrained optimization of wing planforms w.r.t. minimum drag. His results indicate a possible $10 \%$ induced drag reduction for a FSW wing compared to a BSW. Industrial interest to FSW was shown by Lockheed $\mathrm{Co}^{35}$. Their study reports on the design of an isolated FSW and compares numerical and high speed wind tunnel results. Initial problems with high inboard loading and excessive shock strength were overcome by the introduction of a large inboard trailing edge extension.

The planform design for the LamAiR NLF-FSW was done by an engineering trade between aerodynamics and structural mechanics. As already shown by the preliminary design studies, the wing area of $132 \mathrm{~m}^{2}$ is chosen with respect to maximum lift. The span is limited $36 \mathrm{~m}$ by class regulations. A mono-trapezoid wing plan form is chosen because it allows for a full span trailing edge high lift system. Also the leading edge sweep is fixed to $-17^{\circ}$ for reasons of NLF design. This leaves taper ratio and twist distribution the only free parameters to influence the wing's spanwise circulation distribution.

The choice of the circulation distribution is driven by a trade between low root bending moment and minimization of induced drag. Further requirements come from wing section design (local lift coefficient) and allowable spanwise pressure gradients for successful NLF wing design. The selected circulation distribution is given in Fig. 16. Choosing a taper ratio of $\lambda=0.3$ the design circulation is met with minimum twist. The $50 \%$ chord sweep angle is similar to the backward swept reference aircraft (see Sec. I, Fig. 2). Results for the spanwise lift coefficient and the lift increment distributions, calculated by an inviscid lifting line method (neglecting thickness) are shown in Fig. 17. The widely constant lift distribution is seen as favourable for NLF design. Also reduced inboard lift increment will help to avoid the root stall tendency at higher angles of attack.

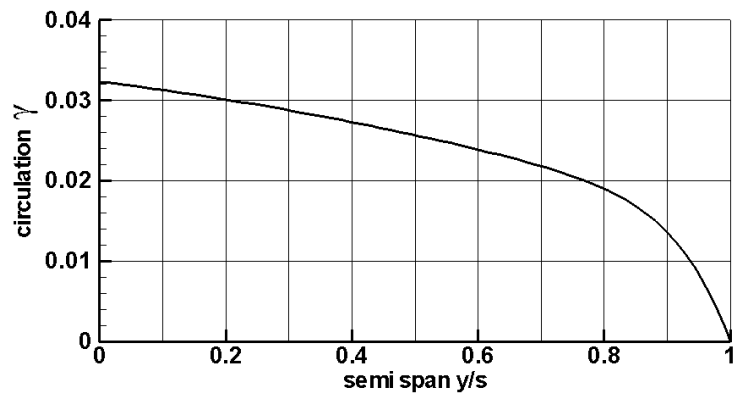

Figure 16. LamAiR design circulation distribution, isolated wing, $\mathrm{c}_{\mathrm{L}}=\mathbf{0 . 5 2}$.

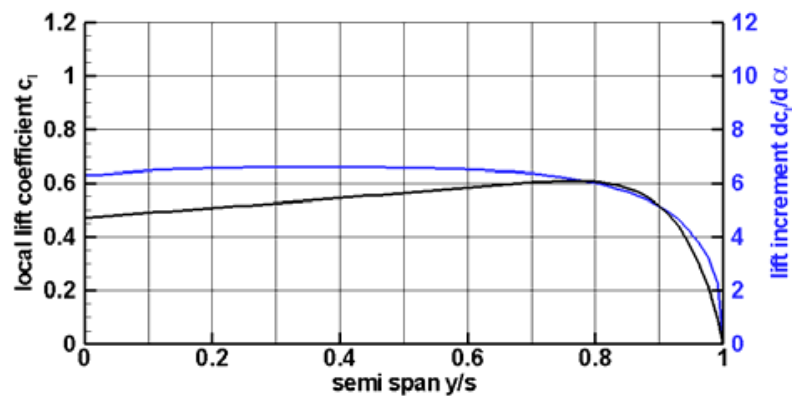

Figure 17. Distribution of local lift (black line) coefficient and lift increment (blue line) for LamAiR wing, $\mathbf{c}_{\mathrm{L}}=\mathbf{0 . 5 2}$. 


\section{CAD based geometry representation}

and CFD meshes

Models used for CFD calculations are based on a parametric CAD description of the LamAiR III configuration as described by preliminary design results (see Sec. II.4). The following components are included to geometry representation: wing, body, belly fairing, simplified generic engine, vertical and horizontal tail surfaces. The model neglects flap track fairings and engine pylons. It features a contoured belly fairing in order to reduce 3D effects at the wing-body-junction (see Fig. 18). For trimming of the horizontal stabilizer, a functional surface is included to the trim horn.

Hybrid CFD meshes are created on the CAD database using commercial software Gridgen $\mathrm{V} 16^{36}$. Different variants (e.g. neglecting tails or engine) are derived. All variants use an identical structured mesh for the wing as shown in Fig. 19. Near surface regions

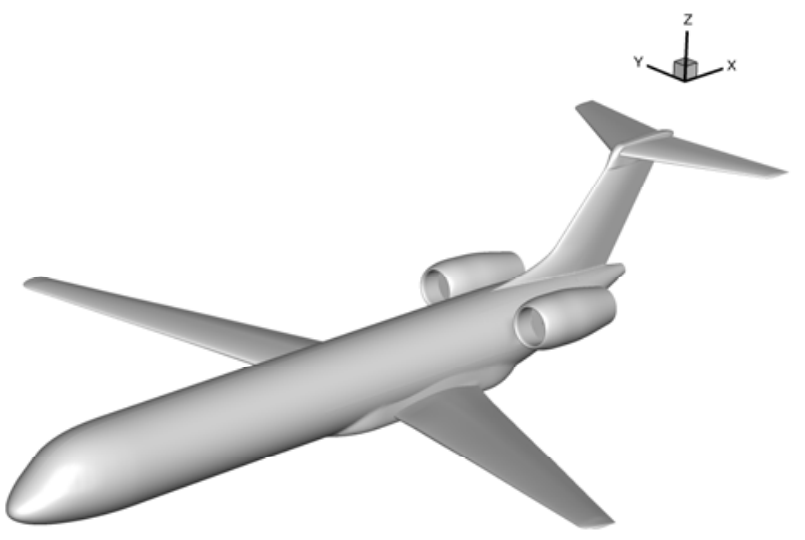

Figure 18. CAD based surface representation of the LamAiR 3 FSW-NLF configuration

are resolved by hexahedral and prismatic cells. Tetrahedral cells fill the remaining computational domain up to the farfield. Utilizing a symmetry boundary condition, the total number of grid nodes is $16 \cdot 10^{6}$ per side of the full configuration. CFD meshes for the reference aircraft are created in the same way with comparable resolution. Here the pylon supporting the under wing mounted engines is included.

\section{Wing Design Stages}

Detailed aerodynamic wing design started by introducing the designed NLF wing section to the basic trapezoid wing planform. The initial twist distribution is calculated by lifting-line theory. CFD results obtained for the wing-body configuration (jig shape wing) revealed a strong inboard shock unsweep (reversal in shock sweep angle) and excessive pre-shock Mach numbers at cruise flight conditions (Fig. 20a). A fair agreement with characteristics of the designed airfoil sections is obtained for mid- and out-board sections of the wing.

To reduce the afore-mentioned inboard problems, several modifications are introduced. The strongest impact is obtained by a modification of the root airfoil and the inboard twist distribution. A contoured belly fairing has been designed with the purpose to reduce $3 \mathrm{D}$ effects at the wing-body junction. It shows being effective in reducing shock unsweep while the desired reduction in inboard pre-shock Mach number is limited to the near fuselage region.

To meet the design circulation distribution, the

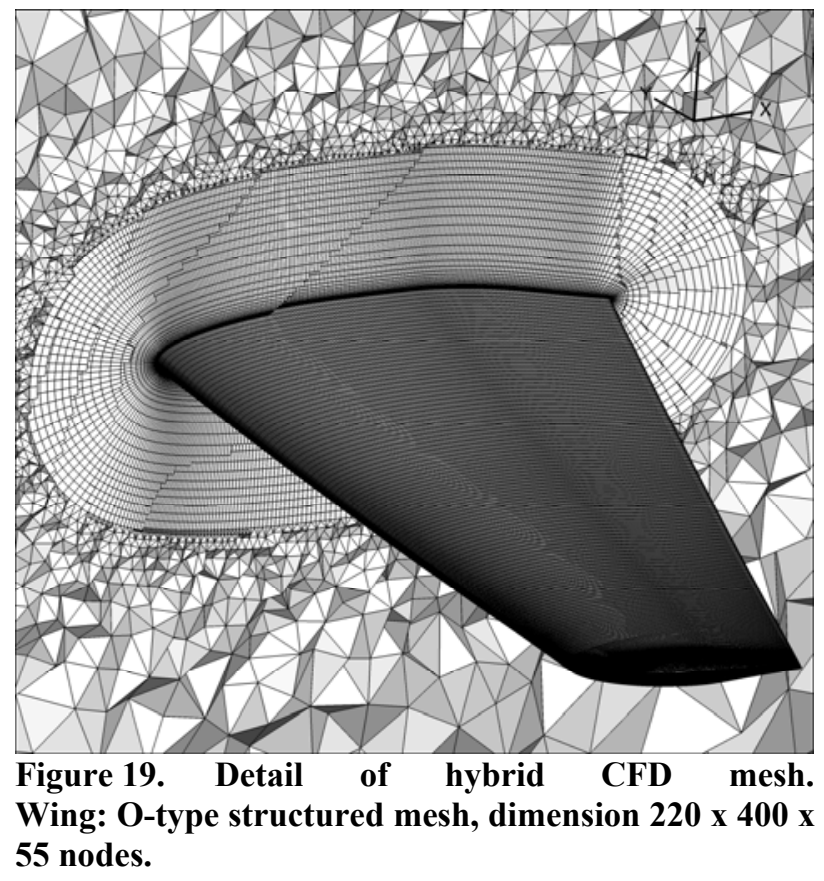
spanwise twist is adjusted. Finally a rounded wing tip is installed, to reduce vortex drag and improve low-speed characteristics. Fig. 20b depicts the impact of the mentioned changes to the configuration. For this intermediate stage of wing design a significant reduction in inboard pre-shock Mach number is achieved. The inboard shock is favorably moved aft but with respect to wave drag the obtained inboard shock sweep angle close to $\varphi_{\text {Shock }}=0^{\circ}$ is still unsatisfying. The overall load distribution has improved by changes to twist and the introduction of the rounded wing tip.

For the final aerodynamic wing design a fully 3D inverse design loop is conducted. Since no inverse design functionality is available for the current TAU-Code version ${ }^{37}$, the respective design routines of DLR's structured CFD solver FLOWer ${ }^{38}$ are adapted to TAU. A residual correction method as introduced by Takanashi ${ }^{39}$ with modifications by Bartelheimer ${ }^{40}$ is employed. The method iteratively reduces the local pressure differences between the current surface pressure and a user prescribed target pressure distribution by local geometry modifications. 
Geometry modifications are obtained by solving the inverse Transonic Small Perturbations (TSP) equation. Coupling of the inverse design routines involves interpolation of geometry and pressure distribution from the CFD solution (TAU-Code, arbitrary hybrid surface grids) to the structured surface grid used to solve the TSP equation. Calculated geometry modifications are transferred back to the CFD grid by volume mesh deformation.

The prescribed 3D target pressure distribution for the wing is derived from the designed NLF airfoil sections (see Sec. III). In spanwise direction straight shock isobars are demanded. The iterative solution is obtained on the flight shape wing with fixed transition locations. At this stage, the operational engine is included to account for engine installation effects in wing design. Results of the inverse design loop after 11 cycles are shown in Fig. 20c. Good agreement between target and achieved pressure distribution is found except for regions of post-shock afterexpansion. Here the prescribed target pressure distribution is not reached and likely to be ill-posed.
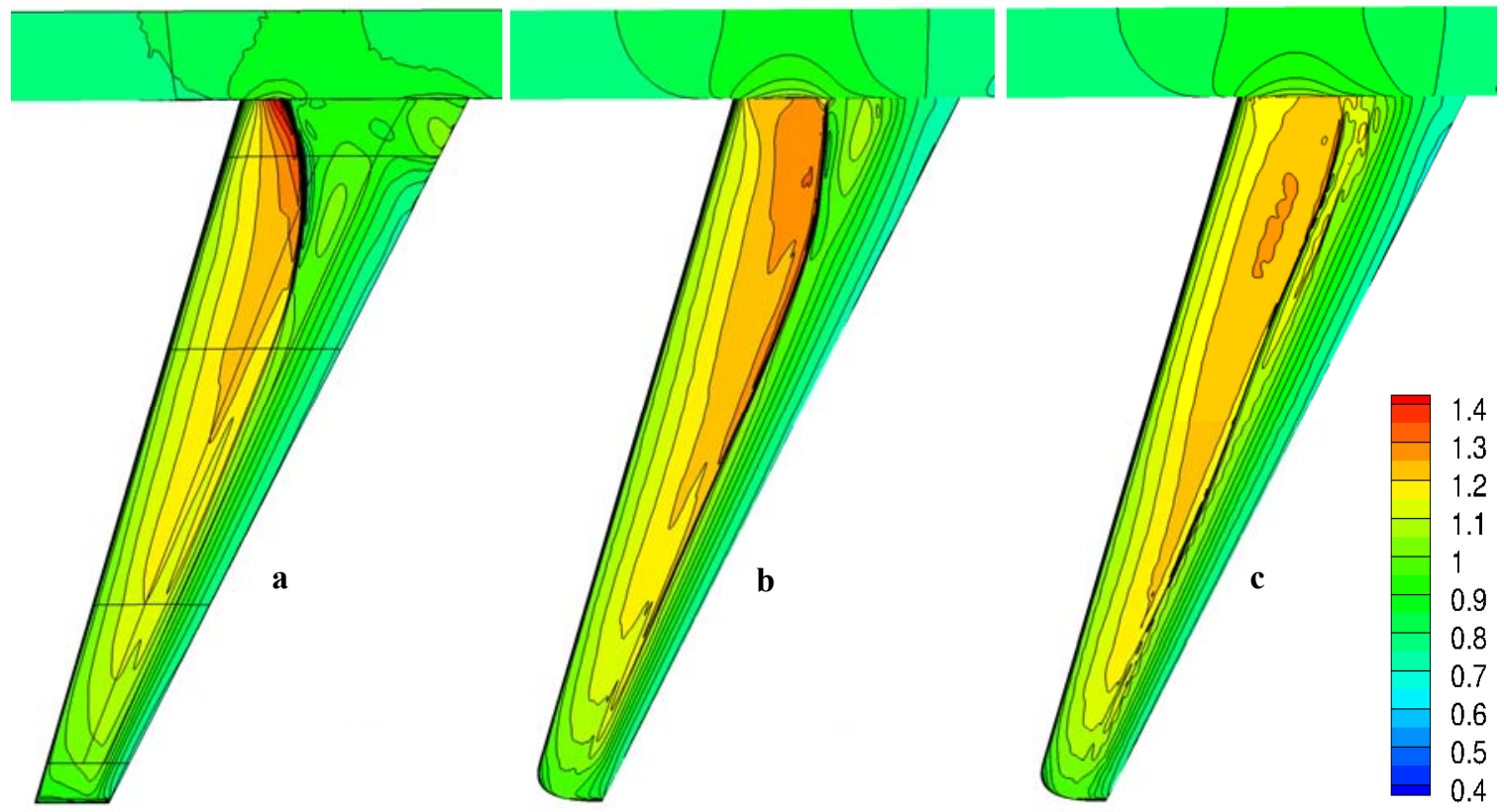

Figure 20. Change of isentropic mach number distribution (upper surface) for selected stages of wing design:

a) conic NLF airfoil sections applied to wing planform (jig shape)

b) manual adjustments to inboard airfoil, belly fairing \& twist, introduction of rounded wing tip (jig shape) c) after 3D inverse design, reduction in shock unsweep and pre-shock mach number (flight shape)

More insight to flow field characteristics of the final aerodynamic wing design is given by Fig. 21 for three spanwise stations. The inboard flow field is characterized by wide extent of supersonic flow over the upper surface ending in an inclined hanging shock with an irregularly shaped after-expansion region. Since this undesirable flow field behaviour does not directly reflect in the contour pressure, it is difficult to foresee for the designer of surfacebased target pressure distributions. For the inboard airfoil the inverse design process has moved the location of maximum thickness aft to match the target pressure distribution. At the mid-board section, again an inclined shock is observed. Here the after-expansion weaker and of regular shape. A shock free re-entry is achieved at the outboard section.

This brief analysis points out the difficulty to design a well behaved transonic flow field just by the definition of a surface pressure distribution. For the current design, some of the NLF related drag benefit is compensated by an increased wave drag. For the purpose of NLF-design inverse methods in general are found very efficient, because the transition location is implicitly described by the target pressure distribution. While currently the target pressure distribution is designed manually, it is likely to become subject to numerical optimization in the future. 


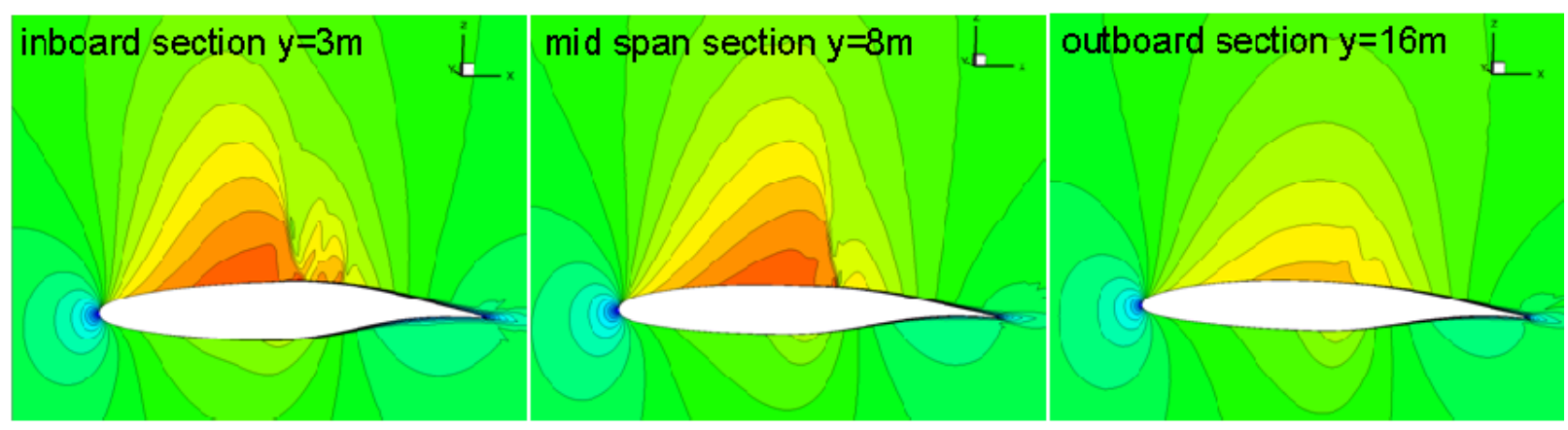

$\begin{array}{lllllllllllllllllllllll}\text { Mach number. } & 0.3 & 0.35 & 0.4 & 0.45 & 0.5 & 0.55 & 0.6 & 0.65 & 0.7 & 0.75 & 0.8 & 0.85 & 0.9 & 0.95 & 1 & 1.05 & 1.1 & 1.15 & 1.2 & 1.25 & 1.3\end{array}$

Figure 21. Mach number contours at three spanwise positions, $M=0.78, c_{L}=0.5$, FL350.

Spanwise distributions of the local twist angle and the relative thickness of sections are given by Fig. 22 for the final wing design. Towards the root section a significant decrease in twist angle is observed. In combination with the modified airfoil contour the twist reduction compensates for the induced angle of attack due to the mid effect of the forward swept wing. While the mid-board section $(\mathrm{y}=4 \mathrm{~m}, \ldots, 12 \mathrm{~m})$ has an almost constant twist, the outboard section is moderately twisted up in order to match the targeted circulation distribution. The spanwise change in twist is driven by planform effects on the load distribution and typical for a forward swept design.

The obtained relative thickness distribution matches structural requirements for a lightweight design. Changes to the initial thickness distribution by the inverse design process are minor and in the order of $\Delta \mathrm{t} / \mathrm{c}=0.005$.

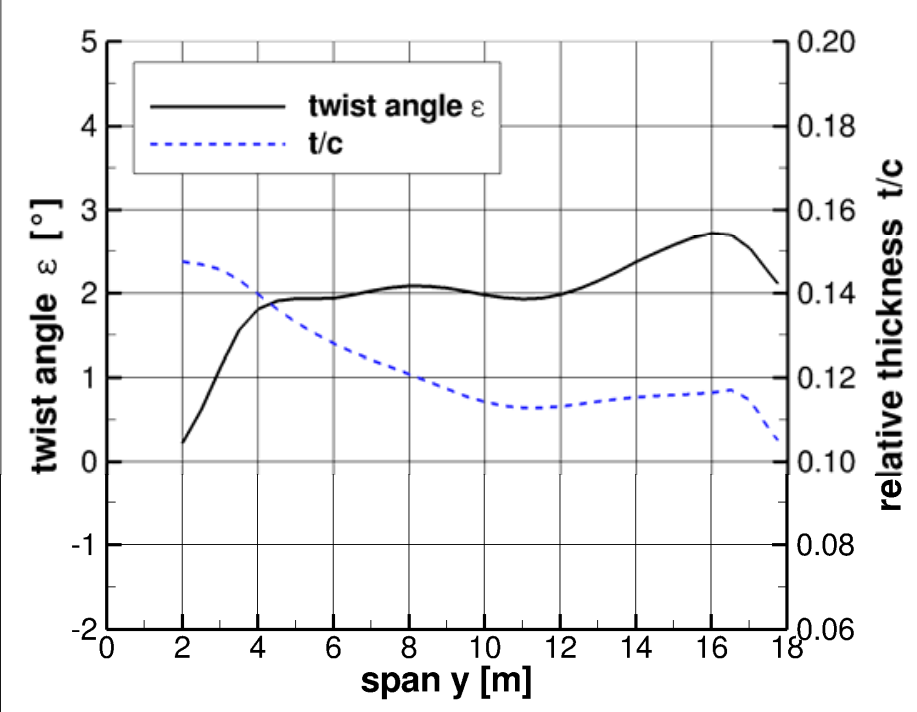

Figure 22. Spanwise twist and relative thickness distributions after of final design. 


\section{B. High-Fidelity Fluid-Structure Coupling}

Fluid-Structure coupled simulations using high-fidelity methods serve as the main analysis method for both, aerodynamic design and aeroelastic tailoring in this study. The coupling chain is shown in Fig. 23. Starting with a flow solution computed on the wing's jig shape, aerodynamic surface forces are interpolated to the finite element grid used by the structural mechanics solver. In response to aerodynamic and inertia forces wing deformations are calculated. To obtain the deformed wing shape, the resulting local structural displacements are transferred to the aerodynamic model by mesh deformation. This process is continued iteratively until equilibrium of aerodynamic and structural forces is found. For the case of wing divergence this state will not be reached, as the wing continues to deform.

Flow solutions are calculated by the DLR TAU-Code ${ }^{36}$, a finite volume based solver for the Reynolds' averaged Navier Stokes Equations. A second order central-differences scheme is employed. Time integration is done by an implicit lower-upper symmetric Gauss-Seidel

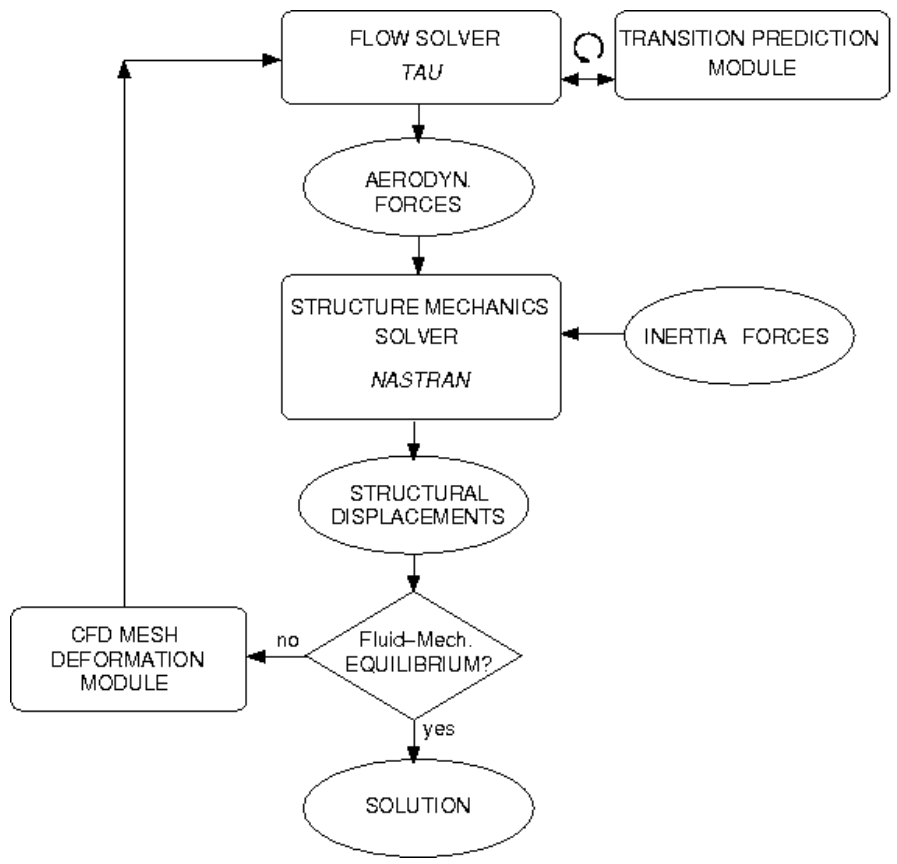

Figure 23. Fluid-Structure-Coupling-Chain (LUSGS) scheme under the assumption of steady state flow solution.

On the structural mechanics side, the commercial finite element solver MSC NASTRAN ${ }^{40}$ is used. In this study the linear static solution sequence SOL101 is run. The neglect of follower forces by this method is seen admissible for the wing deflections regarded here. It is conservative, since an overestimation of wing bending is predicted in case of very large deflections.

For the design of NLF wings, automatic laminar-turbulent transition prediction is a key capability. The TAUCode Transition Module ${ }^{42}$ offers several models to predict transition locations. The procedure chosen here is based on local linear stability theory, predicting the growth of Tollmien-Schlichting- and cross-flow instabilities independently. The local transition position is then found by a 2-N Factor method ${ }^{43}$. Critical $\mathrm{N}$-factors as well as an interaction model of TSI and CFI are derived from flight test data ${ }^{44}$.

The prediction of transition locations is done by an iterative coupling of flow solver and transition prediction module, as shown in Fig. 24. Input data for the linear stability solver is obtained either directly from the Navier-Stokes solution or by running an external boundary layer program. The latter is used in this study. (A detailed description of the process is given by Krimmelbein ${ }^{42}$ ).

In this study, boundary layer stability is evaluated at 24 spanwise positions, each on upper and lower surface of the wing. The resulting discrete transition locations are connected by a polyline, separating laminar and turbulent regions. Within laminar regions, source terms of the turbulence model are switched off.

Storage of the transition location at node-IDs rather than at geometric coordinates allows for geometry alternation by mesh deformation.

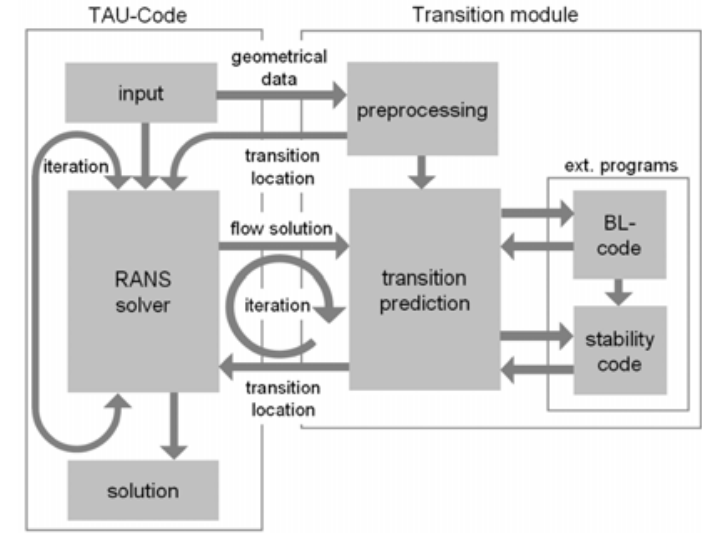

Figure 24. TAU-CodeTransition Prediction Module $^{42}$ 
A comparison of results obtained for jig and flight shape at cruise conditions, depicted in Fig. 25, highlights the importance of fluid-structural coupling to the NLF design process. Due to aerodynamic and inertia loads, the wing bends upwards. Because of the aeroelastic tailoring of the wing structure, a slightly negative twist is obtained. The effect on the pressure distribution is evaluated at the outboard section $y / s=0.875$. It can be seen that the aeroelastic deformation leads to a natural load alleviation. Although the change in $\mathrm{c}_{\mathrm{p}}$-distribution is small, the subsequent change of the lower surface transition position is significant. Here, the slight pressure increase near the leading-edge leads to a rapid transition by Tollmien-Schlichting-Instabilities. The ability to detect such phenomena is only possible by coupled aero-structural simulations with automatic transition prediction. It should be noted that configuration shown in Fig. 25 is not the final design stage, but only used for demonstration purposes here.
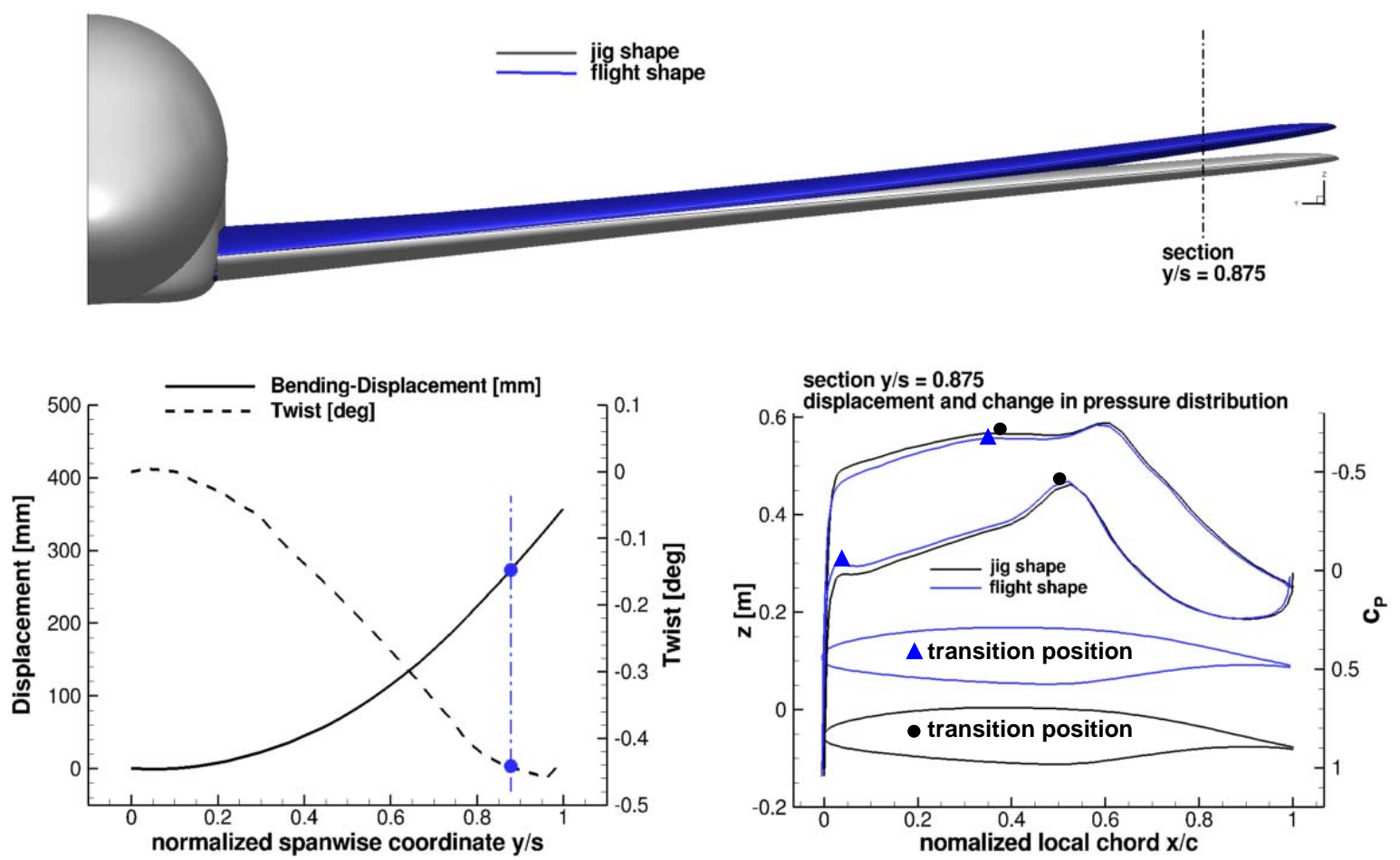

Figure 25. Deformation of the aeroelastically tailored forward swept wing in cruise flight $\mathrm{M}=0.78, \mathrm{c}_{\mathrm{L}}=0.45, \mathrm{FL}=350$, fuel mass $=8050 \mathrm{~kg}$ upper: wing bending, jig shape vs. flight shape lower left: spanwise bending and torsional displacement of the wing box (flight shape) lower right: outboard section pressure distribution, load alleviation due to aeroelastic tailoring and impact aeroelastic deformation on local transition position 


\section{Structural Model}

For the wing structure carbon fiber reinforced plastic (CFRP) material is used. Unidirectional tapes are combined with fabrics for shear-bearing layers. A classical monolithic two spar design with discrete integrated stiffeners in the upper and lower skin is considered. The direction of the stiffeners follows the main fiber direction of the skin laminates whereas equidistant ribs are oriented in streamwise direction (Fig. 26). The assembly concept which is gapless and has no rivets on the outside meets the surface requirements for laminar flow design. In this preliminary design stage connections are not explicitly modeled, i.e. the structural components are connected by direct nodal connections.

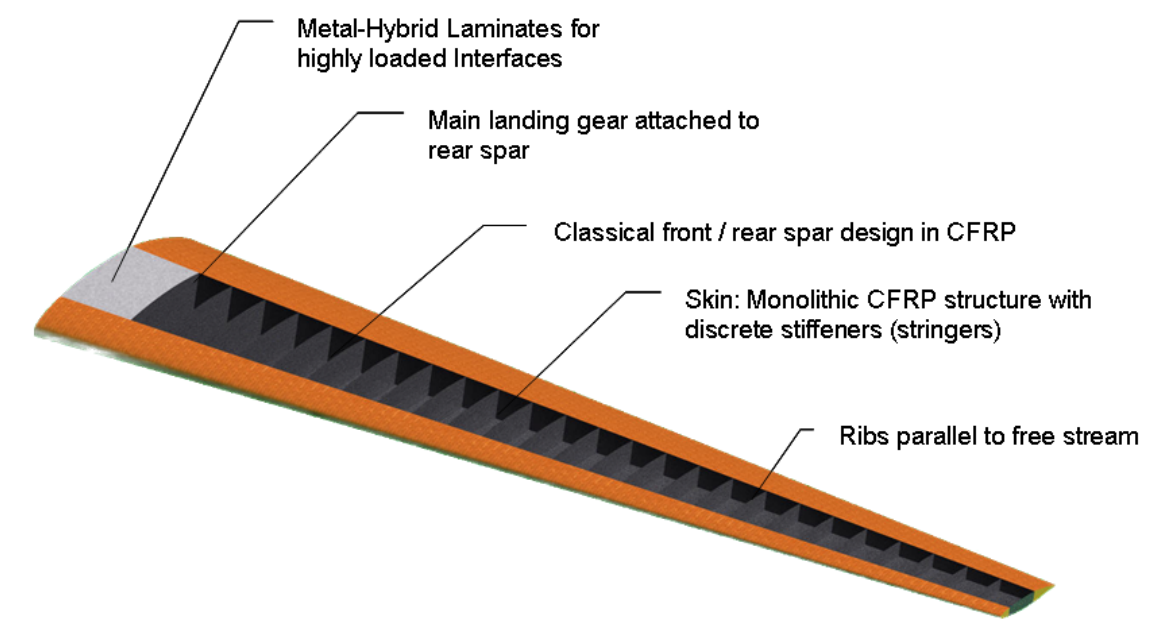

Figure 26. General layout of LamAiR wing box

The finite element model consists of shell elements with bilinear shape functions. In the pre-design stage, stringers are modeled as smeared thickness of the skin. The discretization is chosen to be small enough to represent the load distribution accordingly and to resolve panel buckling and panel waviness, whereof the latter is a surface requirement for laminar flow. To also consider the local waviness between stringers, a more detailed model with discretized stiffeners was investigated, but not presented in this paper.

High lift devices are modeled in simplified terms, i.e. the cross section is continuous across the entire profile. By this means the pressure loads acting on these areas are transferred to the load-bearing wing box. In order to be nonload-bearing itself, the high lift areas are modeled with an artificial stiffness on the material level. The mass of the high lift devices is condensed to the spar positions. This is considered to be sufficient for the quasi-static analyses. Quantitatively the structural masses are based on a semi-empirical study whereas the fuel masses and their distribution are deduced from the design mission and the wing geometry respectively. The total load concept by MSC Patran ${ }^{45}$ is used to model the fuel mass, i.e. a desired force vector is equally distributed to the upper or lower skin, depending on the load case.

From the structural side only one half of the wing is modeled including the center wing box. The wing loads are reacted in the symmetry plane. Additional stiffening due to the fuselage frames is considered at the junction.

\section{Structural Sizing and Aeroelastic-tailoring}

In the preliminary design phase, the choice of relevant dimensioning load cases is a key issue. On the contemplated cost-intensive level a limited set of critical load cases has been chosen. The main requirements were to couple the flexural deformation of the wing to a minimum rotation for the cruise flight and avoid divergence for all flight conditions. For the structural integrity, two load cases with the maximum dynamic pressure were selected based on PrADO calculations, namely a symmetric maneuver load case with maximum negative load factor and a gust load case with maximum load factor. A short description of these three considered load cases is given in Table 5 (case 1 to 3 ) and the corresponding wing bending and tip rotations are shown in Fig. 29. The loads in the aeroelastic equilibrium were taken for a gradient-based SOL200 sizing loop in which damage tolerance and stability were identified as the main design drivers. For the layups, common limitations like symmetry and angular balance were taken into account. 
For a chosen structural configuration, a parameter study was performed in which the main fiber direction of upper and lower skin, previously identified as having the biggest sensitivity, were varied simultaneously. The aeroelastic equilibrium in cruise flight was derived for five different tailoring angles. Starting point was the original configuration (Fig. 27) showing the desired negative coupling of bending and twist but based on an uncoupled pre-design. From there, the main fiber direction was turned back in steps of 5 degrees. The resulting displacements based on the rigid and the flexible wing can be seen in Fig. 28. Each point represents the calculated z-displacement and y-rotation, evaluated at the rib positions. This comprehensive

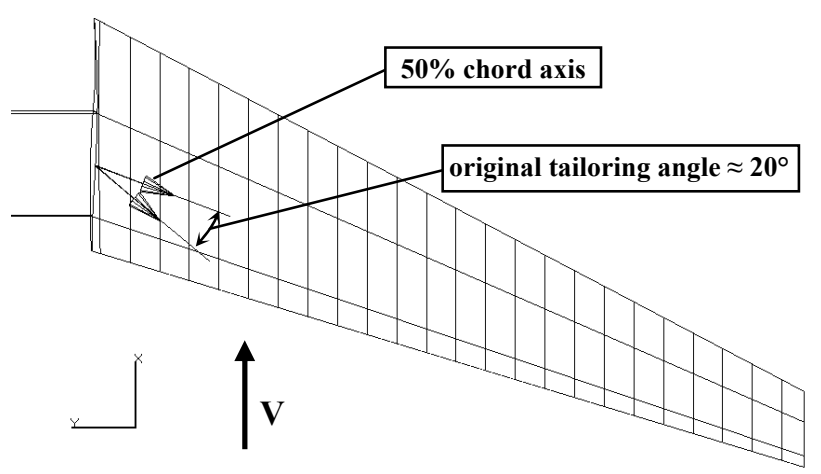

Figure 27. Wing top view with tailoring range depiction implicitly shows the wing axis from left to right due to displacement continuity.

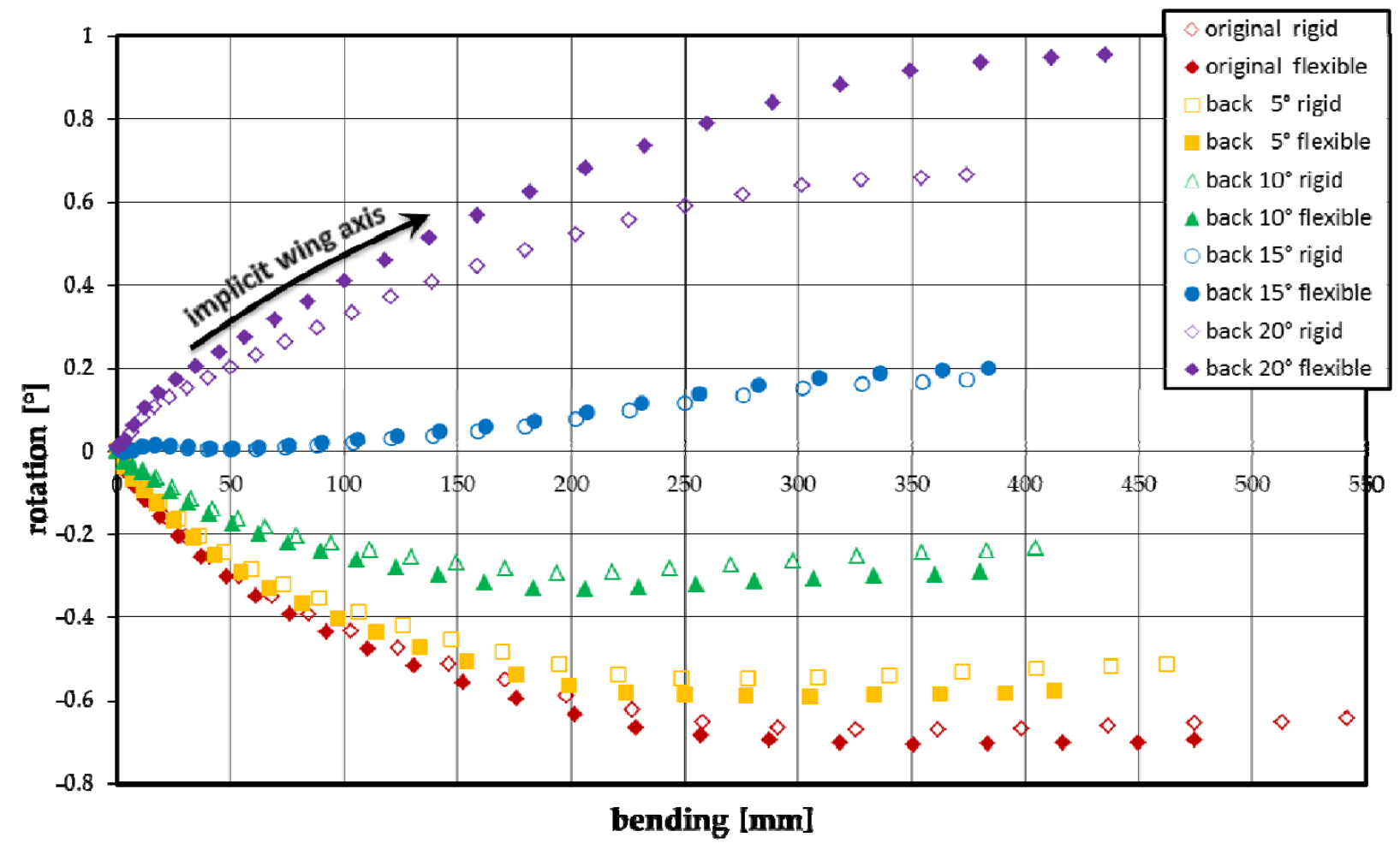

Figure 28. Wing displacement in cruise flight for different tailoring angles

Two main conclusions can be drawn from this study, concerning the impact of the aeroelastic tailoring and the coupled simulation. In cruise flight, the original configuration shows a wing bending coupled to a negative rotation (decrease in angle of attack). This so-called washout leads to an alleviated lift distribution and hence reduces the wing bending. Turning the main fiber direction back successively increases the rotation while decreasing the bending. The chosen configuration would have a non-twisting wing and the highest stiffness for an angle of roughly $12^{\circ}$ backwards, related to the original direction. For a positive coupling the contrary is the case, i.e. the load becomes self-energizing. 
For each tailoring angle the deformation resulting from the loads on the rigid wing (rigid) and the deformation at the aeroelastic equilibrium (denoted as flexible) are shown. This illustrates the redistribution of the loads. The

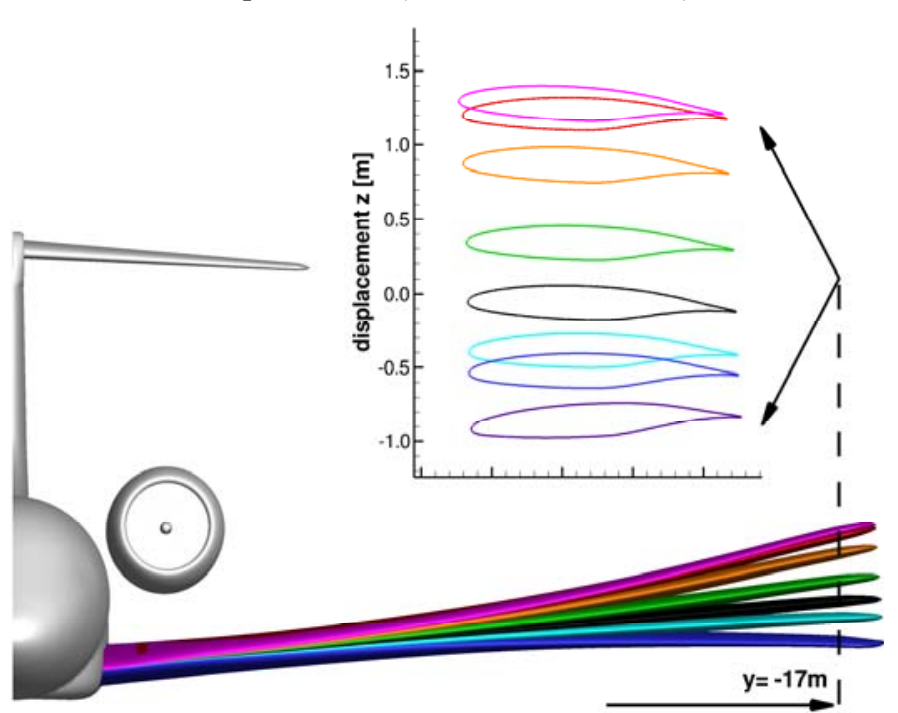

Figure 29. Wing bending and tip section displacement.

\begin{tabular}{cccccccc}
\hline case & $\begin{array}{c}\text { color } \\
\text { code }\end{array}$ & $\begin{array}{c}\text { Mach } \\
\text { Number }\end{array}$ & $\begin{array}{l}\text { Lift } \\
\text { coef. }\end{array}$ & $\begin{array}{c}\text { Load } \\
\text { factor }\end{array}$ & $\begin{array}{l}\text { Fuel } \\
\text { mass }\end{array}$ & $\begin{array}{l}\text { vertical } \\
\text { displ. }\end{array}$ & $\begin{array}{l}\text { rotation. } \\
\text { displ. }\end{array}$ \\
\hline & & $\mathrm{M}$ & $\mathrm{c}_{\mathrm{L}}$ & $\mathrm{n}_{\mathrm{z}}[\mathrm{g}]$ & $\mathrm{m}_{\mathrm{F}}[\mathrm{t}]$ & $\Delta \mathrm{z}[\mathrm{m}]$ & $\left.\Delta \alpha{ }^{\circ}\right]$ \\
0 & & - & - & 0 & 0 & 0 & 0 \\
1 & & 0.78 & 0.50 & 1.0 & 17 & +0.51 & -0.6 \\
2 & & 0.67 & 0.42 & 3.4 & 17 & 1.25 & -1.2 \\
3 & & 0.67 & -0.15 & -1.0 & 2.98 & -0.81 & -4.6 \\
$4 \mathrm{a}$ & & 0.45 & 0.59 & 2.5 & 2.98 & 1.37 & -0.1 \\
$4 \mathrm{~b}$ & & 0.45 & 0.93 & 2.5 & 15.4 & 1.98 & +1.0 \\
$5 \mathrm{a}$ & & 0.45 & -0.24 & -1.0 & 2.98 & -0.49 & -2.1 \\
$5 \mathrm{~b}$ & & 0.45 & -0.37 & -1.0 & 15.4 & -0.70 & -2.4 \\
\hline
\end{tabular}

Table 5. Wing bending and tip section displacement. original, negatively coupled wing alleviates the loads in spanwise direction. Taking into account this alleviation by fluid-structure-calculation gives the corresponding change in the deformed shape, i.e. a negatively coupled wing leads to a reduction in the displacement and vice versa.

The final configuration is a tradeoff that satisfies the constraints of being free of torsional divergence at a minimum of bending-twist coupling at cruise conditions. The final layout came up with a main fiber direction of $11^{\circ}$, relative to the $50 \%$ wing box axis and a corresponding mass of $3942 \mathrm{~kg}$. This is a saving of $7.5 \%$ compared to the aluminum wing-box of the reference aircraft.

Figure 29 shows the wing bending and tip deflection for various load cases given in Table 5. It is observed that not only the lift coefficient and load factor have an impact on torsion of the wing but also the lift force- and fuel mass distribution. While the local center of pressure is close to the wing's elastic axis, aeroelastic tailoring effectively reduces geometric bending-torsional coupling. In cases where the local center of pressure moves toward the leading edge (i.e. low Mach numbers at high $\mathrm{c}_{\mathrm{L}}$ ), the outboard wing sections show an increase in local angle of attack due to the acting aerodynamic pitching momentum. For all considered load cases the aeroelastic equilibrium is obtained, i.e. no torsional divergence occurs. For the load cases investigated, there is no objection from the structural point of view. 


\section{Aerodynamic Performance Assessment}

To assess the aerodynamic performance of the forward swept NLF wing, numerical simulations with aerostructural coupling and automatic transition prediction are conduced. All results shown in this section are calculated for the wing-body-engine configuration with a constant thrust setting. Therefore aerodynamic interferences between engine and wing are included.

For steady horizontal cruise flight the pitching momentum with respect to the center of gravity must be zero. To calculate the drag polar of the trimmed aircraft the lift of the horizontal tail plane and the required engine thrust has been considered with an analytical model. For the trim drag a quadratic drag polar for the horizontal tail plane is assumed and the constant thrust in the CFD simulation is replaced with the required thrust to overcome drag. Span efficiency and zero-lift-drag of vertical and horizontal stabilizer surfaces is provided by separate CFD solutions for the full configuration including tail surfaces. The presented drag data does not include the thrust specific drag of the engine.

\section{A. Design Point Analysis}

At the design point of the aircraft $\left(\mathrm{c}_{\mathrm{L}}=0.5, \mathrm{M}=0.78, \mathrm{FL} 350, \mathrm{~m}_{\mathrm{F}}=17 \mathrm{t}\right)$ optimal performance is expected. As shown in Figure 30, the design requirement for a wide extend of laminar flow is fully achieved. On the wing's upper surface the transition line reaches up to the local pressure minimum $\left(\mathrm{x}_{\mathrm{T}} / \mathrm{c}=45 \%\right.$ inboard and up to $60 \%$ outboard) except near the wing body junction. Here, a turbulent wedge is seen, caused by bypass transition due to the turbulent fuselage flow. The development of the turbulent wedge can not be influenced by means of NLF design. On the wings lower surface the situation is similar. The lower surface transition location is at $50 \%$ local chord for most of the wing span. Towards inboard sections $(\eta<0.3$ ), a stronger amplification of cross-flow instabilities is observed, gradually shifting the transition line close to the leading edge $(\eta<0.15)$. Like for the upper surface the most inner section is affected by bypass transition.

In comparison to a fully turbulent solution for the same configuration (at identical $\mathrm{c}_{\mathrm{L}}$ and flow conditions) the achieved drag reduction is $12.6 \%$ (36 d.c.). Friction drag reduction contributes $49 \%$ to total drag reduction, leaving a $51 \%$ share to reduction in viscous pressure drag.

Figure 31 gives a detailed drag breakdown for the wing of the FSW-NLF aircraft. Because of the afore mentioned reduction of viscous pressure drag and friction drag, the relative shares of lift induced drag and wave drag to total drag increases. With a lift to drag ratio of 19.9, the designed FSW-NLF offers an outstanding aerodynamic performance at design conditions.

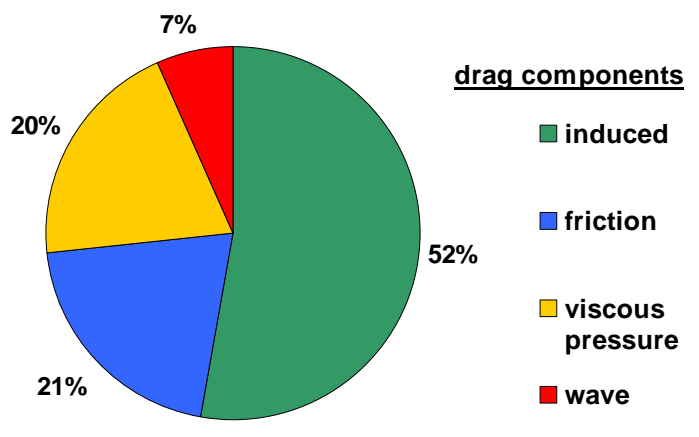

Figure 31. Drag breakdown for the Wing of the FSW-NLF at design flight conditions.

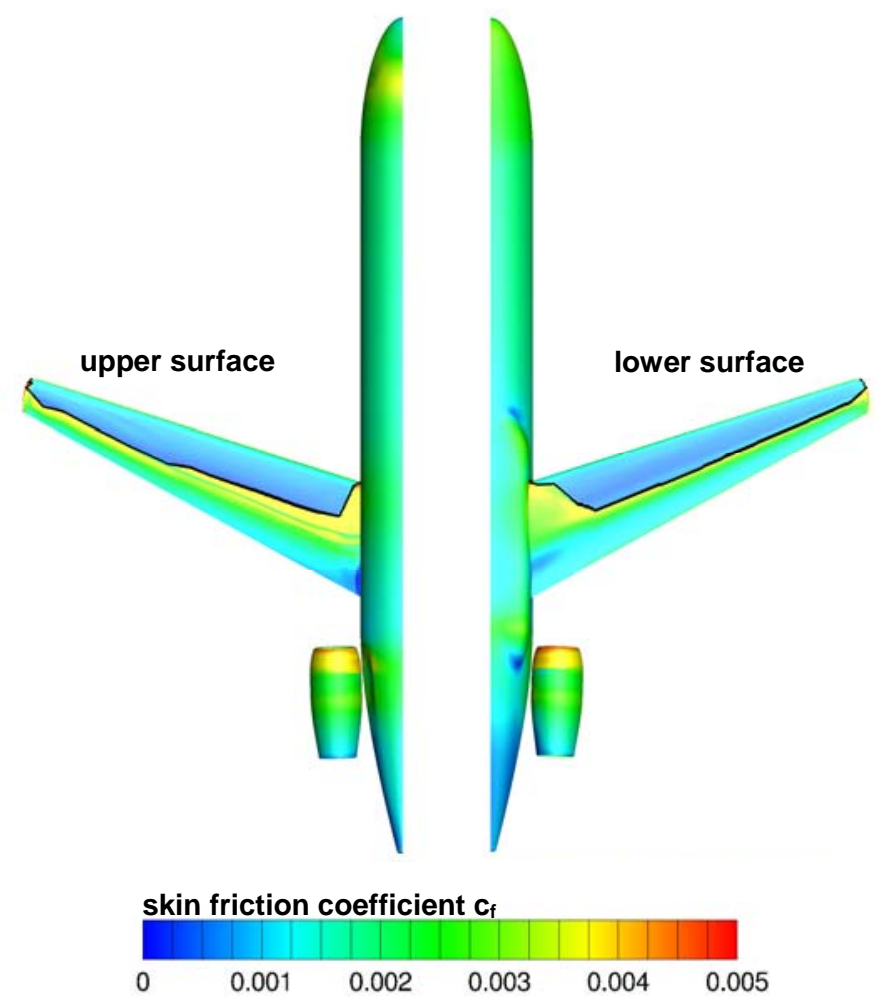

Figure 30. Transition location (black line) and skin friction contour. $c_{L}=0.5, M=0.78, F L 350$ 


\section{B. Drag Polars}

With respect to aircraft cruise performance, numerical simulations for a variation of the lift coefficient are conducted for the FSW-NLF aircraft and the backward swept reference aircraft. The $\mathrm{c}_{\mathrm{L}}$-range investigated so far is 0.4 to 0.65 at $\mathrm{M}=0.78, \mathrm{FL} 350, \mathrm{~m}_{\mathrm{F}}=17 \mathrm{t}$. Results from this study are reproduced in Figure 32 .

With respect to the drag coefficient, the FSW configuration with natural transition offers a clear benefit over the range of regarded lift coefficients. Under fully turbulent conditions, the drag polar of the FSW aircraft is comparable to the backward swept reference. Yet, for lift coefficients below $c_{L}=0.52$ its drag coefficient is approximately 10 d.c. less than the one of the reference. A closer look to the drag polar of the FSW-NLF reveals a region of almost constant drag coefficient. This effect is not due to a laminar bucket, but related to the occurrence of a shock induced corner separation at the junction of upper wing and belly fairing. It is still under investigation why the fully turbulent solution is not affected by this undesirable flow phenomenon.

Plotting lift-to-drag ratio vs. lift coefficient (Figure 33) the aerodynamic advantage of the NLF wing near its design point becomes even more pronounced. A wider optimum and better L/D - performance at lift coefficients lower than $c_{L}=0.5$ is accessible to the NLF configuration once the mentioned corner separation is successfully suppressed.

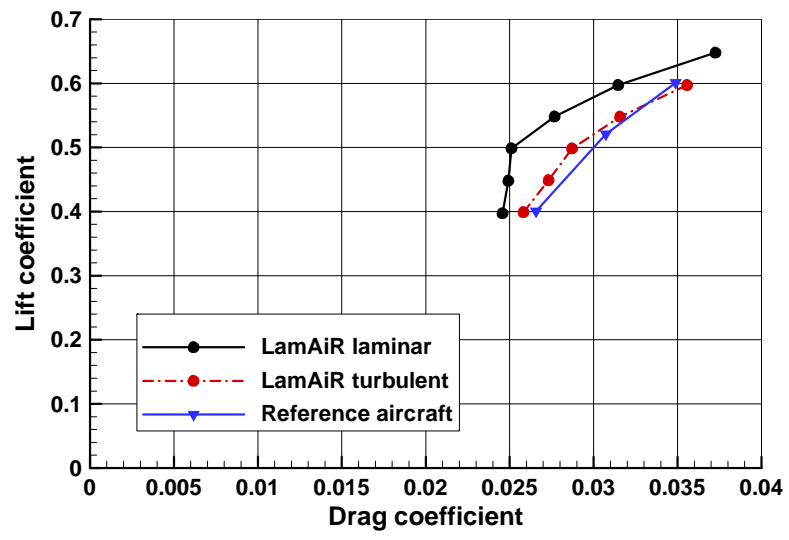

Figure 32. Polars of the LamAiR FSW configuration with transition prediction (NLF), fully-turbulent analysis (turbulent) and the BSW reference aircraft configuration.

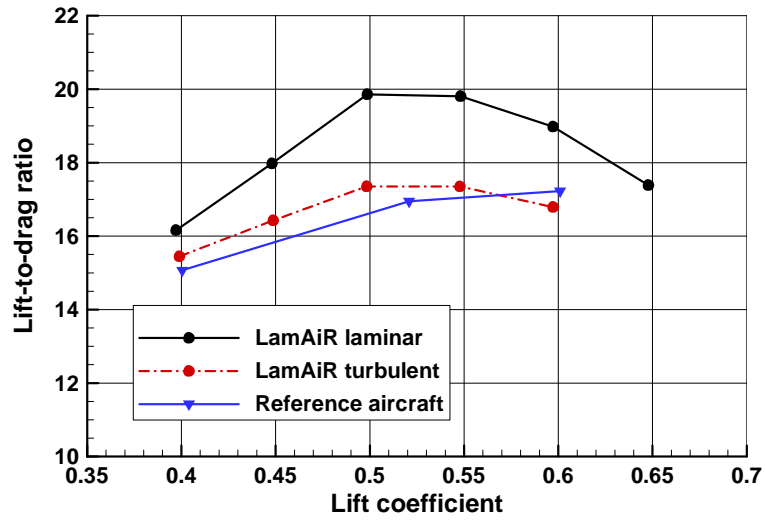

Figure 33. Lift-to-drag ratios of the LamAiR FSW configuration with transition prediction (NLF), fully-turbulent analysis (turbulent) and the BSW reference aircraft configuration.

\section{Mach number variation}

For the FSW-NLF configuration a variation of cruise flight Mach number is conducted. The study is carried out for a fixed lift of $670 \mathrm{kN}$ at flight level 350 , carrying $17 \mathrm{t}$ of fuel. Results with respect to the aircraft's performance are shown in Figure 34. Plotted are the lift-to-drag ratio and the aerodynamic figure of merit $\mathrm{M} \mathrm{x} \mathrm{L/D} \mathrm{against} \mathrm{Mach}$ number. Lift-to-drag ratio is highest at $\mathrm{M}=0.76$ but only a marginal decrease is observed when increasing cruise speed up to $\mathrm{M}=0.78$. The figure of merit has its optimum at the design Mach number $\mathrm{M}=0.78$. Increasing the Mach number to $\mathrm{M}=0.8$, a significant reduction of lift-to-drag ratio is seen. Flow field inspection has shown that the inboard shock strength increases. Performance losses due to a high wave drag are the consequence. Nevertheless, the installed engine power would be sufficient to overcome the thrust requirement of $44 \mathrm{kN}$, allowing the FSW-NLF for high speed cruise at $M=0.80$. A further finding of the study is that characteristics of the section pressure distributions are widely unchanged upstream of the shock. Under these conditions laminar flow can extend up to the local shock position unless a previous adverse pressure gradient enforces transition to turbulence.

\section{Flight altitude variation}

The change in aircraft performance due to a variation of flight altitude is studied at a constant lift force of $670 \mathrm{kN}$ at $\mathrm{M}=0.78$. The fuel mass is fixed to $\mathrm{m}_{\mathrm{F}}=17 \mathrm{t}$. Three flight levels are considered: FL300, FL350 and FL400. Results of this study are given in Figure 35. Raising the flight altitude from FL350 to FL400 only a marginal decrease of the lift-to-drag-ratio is observed. The lower density at FL400 requires for a lift coefficient of $c_{L}=0.63$ to remain level 
flight. Hereby the shock strength and consequently wave drag is increased but on the other hand the lower Reynolds number at this altitude reduces friction drag and is of advantage with respect to laminar flow.

At FL300 the lower required lift coefficient moves the shock position upstream, reducing the possible laminar flow extend. Further, the previously observed corner separation at the wing-body junction reappears, causing a significant increase in pressure drag.

\section{E. Fuel mass variation}

Finally we like to study the effect of a varying the fuel mass with respect to aerodynamic performance. Operating at design flight conditions $\left(\mathrm{M}=0.78, \mathrm{c}_{\mathrm{L}}=0.5\right.$, FL350), numerical simulations were conducted for the wing carrying 5.0t, 11.0t or 17.0t of kerosene. The distribution of fuel mass is unchanged for all cases. Although wing bending reacts to the changing inertia load, the bending-torsional coupling of the aeroelastically tailored wing prevents against a relevant change in elastic twist. The extent of laminar flow is remains unaffected. The predicted difference in drag coefficient for $\mathrm{m}_{\mathrm{F}}=5.0 \mathrm{t}$ and $\mathrm{m}_{\mathrm{F}} 17 \mathrm{t}$ is less than 4 drag counts. Considering flight operations of a NLF aircraft, this result is very favourable.

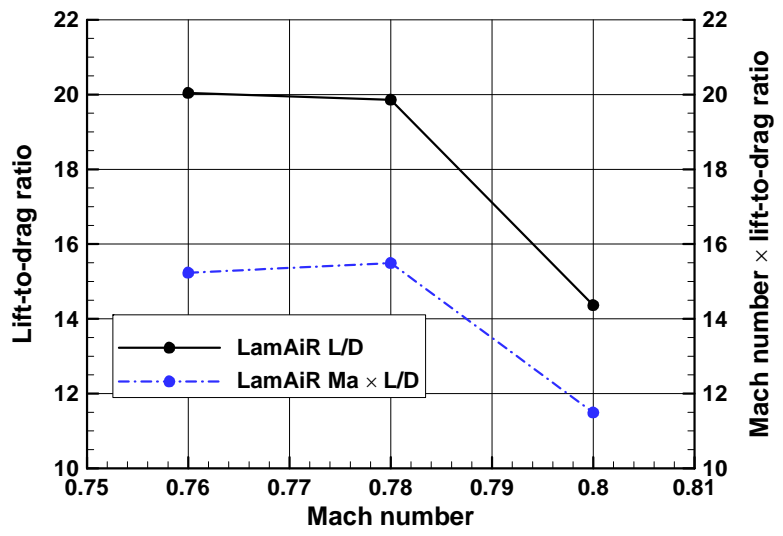

Figure 34. Mach number variation of the LamAiR FSW-NLF configuration with transition prediction.

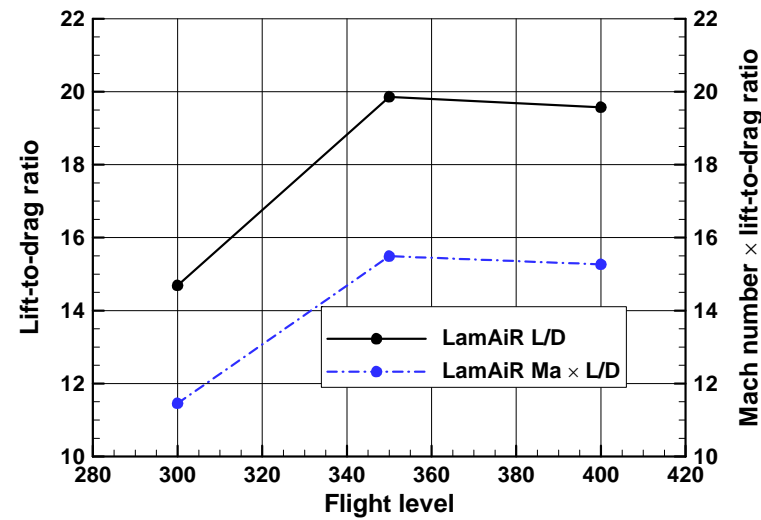

Figure 35. Flight level variation of the LamAiR FSW-NLF configuration with transition prediction.

\section{F. Comparison of CFD results with the preliminary aircraft design model}

For estimation of the profile drag in preliminary aircraft design using PrADO, the model for the laminarturbulent transition as described in Sec. II.C is used. To compare the predictions by this simplified model with the laminar-turbulent prediction of the high fidelity simulations (Sec. V.a), the transition lines are shown in Figure 36 for the aircraft's design point. As mentioned in Sec II.C, the preliminary aircraft design model does not differentiate between the upper and lower side of the wing. With exception of the tip and inboard region of the wing the agreement of the preliminary aircraft design model and the high fidelity transition prediction is very good as shown in Fig. 31. The difference between the PrADO model and the CFD simulations in terms of the laminar area is only $1.6 \%$. It should be noted that the high level of agreement is achieved by calibration of the transition model using data from wing section design. Therefore the model's validity is limited to cruise flight conditions of the current FSW-NLF design.

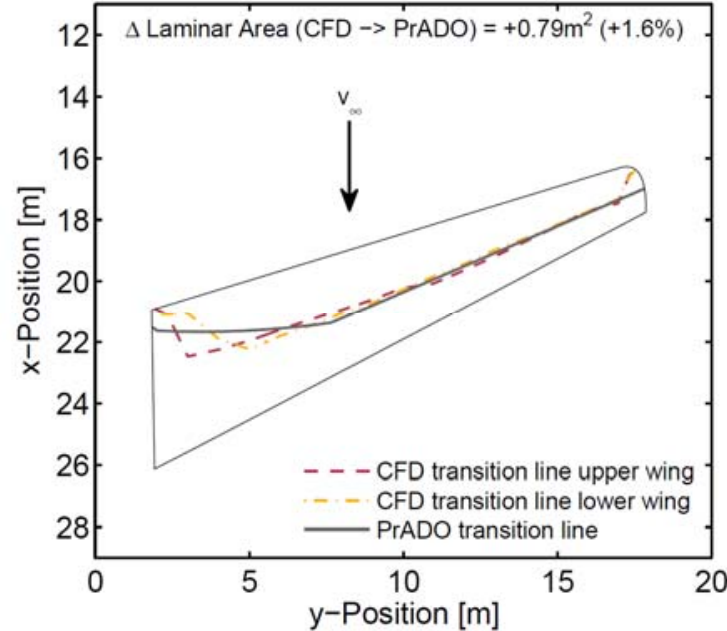

Figure 36. Comparison of spanwise transition location, CFD results vs. preliminary design transition model. 
Figure 37 gives a comparison of the spanwise circulation and lift distribution obtained by preliminary design aerodynamics of PrADO and the CFD results. The spanwise agreement of results is very good. In the region of the fuselage $(y<2 \mathrm{~m})$ existing differences are explained by the simplified treatment of the fuselage in the lifting line method employed by PrADO.

The adoption of the imposed design circulation concept (see Sec. IV, Fig. 16) by preliminary aircraft design and high fidelity models results in a fair agreement of results.

In terms of drag forecasts, the careful calibration of the preliminary design methods has paid-off. The predicted maximum lift-to-drag ratio is obtained for the same lift coefficient and differs only by a $\Delta \mathrm{L} / \mathrm{D}$ of 0.7 .

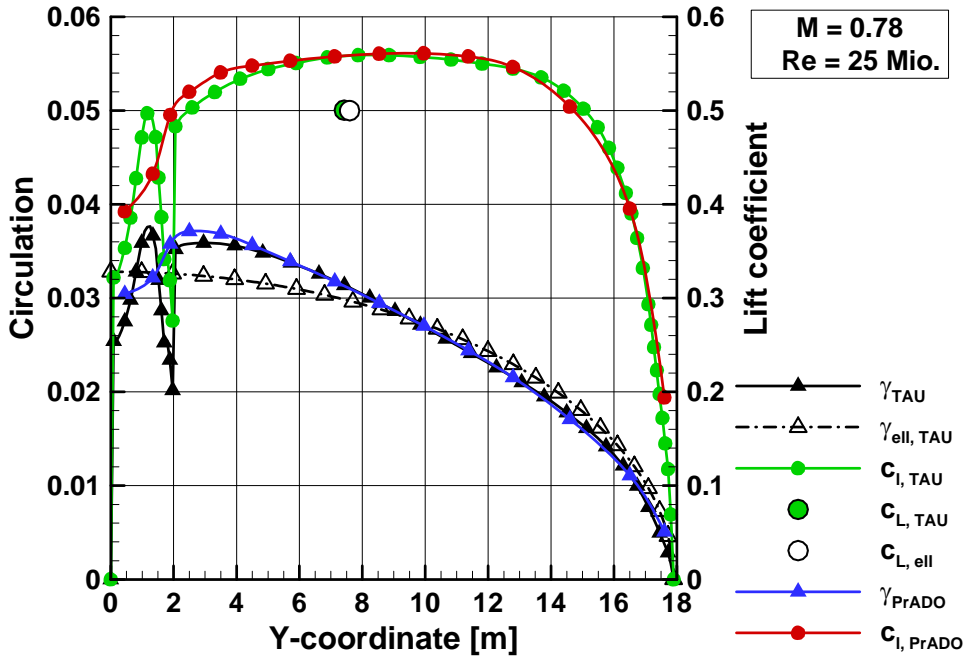

Figure 37. Comparison of spanwise circulation and lift coefficient distribution, CFD results (TAU) vs. preliminary aircraft design model (PrADO).

\section{Conclusion and Outlook}

A conceptual study of a transonic NLF transport aircraft with forward swept wings has been conducted. It was shown that the concept of a forward swept wing enables for natural laminar flow over a wide extent of the wing at a design cruise Mach number of 0.78. Aeroelastic tailoring of the CFRP wing box has been developed and applied to control the aeroelastic bending-torsional coupling of the wing. It was shown for limited set of load cases, that the design is capable to prevent torsional divergence.

For the assessment of the FSW-NLF concept on aircraft level, configurational studies using preliminary design methods were conducted. The FSW-NLF configuration selected for further investigation features an aerodynamically clean wing, rear-mounted engines and a T-tail. Compared to under-wing mounted engines, the aftmounted engine position is found to increase the fuel consumption by about $3 \%$ but offers advantages for the integration of future high-bypass engines. The benefit of laminar flow for this concept is a total reduction in fuel consumption by $9 \%$ in comparison to a conventional BSW turbulent reference aircraft.

The modelling of laminar flow at preliminary design level is based on results obtained by high-fidelity NLFairfoil section design. Here, a novel inverse design approach was used for NLF-airfoil sections creation, accounting for wing sweep and taper. The developed airfoils show wide extents of laminar flow. They feature a comparably high nose radius for NLF airfoils and comply with structural thickness requirements of wing design.

Application of the designed NLF sections to the trapezoidal wing planform has shown good agreement with the target pressure distribution for outboard wing sections, while inboard sections suffer from shock unsweep and excessive pre-shock Mach numbers. These 3D effects are caused by the mid effect of forward swept wings and displacement effects of the fuselage. A reshaping of affected sections by a 3D inverse design method under consideration of aeroelastic deformations has been conducted. This approach has led to a favourable 3D pressure distribution at the aircraft's design point.

For the structural sizing of the wing-box, a limited set of load cases has been considered, including critical gust and maneuver loads. The influence of the principle laminate axis of the CFRP laminate has been parametrically varied to fulfill the aeroelastic requirements with respect to torsional divergence and laminar flow. Compared to an all-aluminum wing-box of a backward swept wing, the CFRP wing-box for the FSW-NLF configuration allows for mass reduction in the order of $7 \%$. 
First results from aero-structurally coupled simulation with coupled transition prediction confirm that a large extent of laminar flow is achieved on the wing's upper and lower surface. At the design point of the FSW-NLF configuration a drag reduction of $12.6 \%$ is obtained from laminar flow compared to fully turbulent results. With respect to the BSW turbulent reference aircraft the gain is $18 \%$. For off-design conditions, simulations predict a corner separation at the wing-body junction. Despite of this bubble, drag levels remain low, as laminar flow is unaffected. Assumptions for the extension of laminar flow used in preliminary design studies have been confirmed by high-fidelity results.

The main conclusion from the studies conducted so far is that a forward swept wing transport aircraft allows for a successful natural laminar flow design at high cruise mach numbers without excessive structural weight penalties. DLR will continue its research on this promising concept. Further investigations are planned for a multidisciplinary optimization of the wing including studies for suited high-lift concepts. With regard to stability and control of the presented FSW-NLF configuration, low-speed wind tunnel tests are planned. Open questions remain with respect to operational aspects of laminar flow aircraft, i.e. insect contamination, icing and fuel planning.

Flight mission analysis and market studies for the designed LamAiR FSW-NLF aircraft will be presented at the ICAS Conference, Brisbane 2012.

\section{References}

${ }^{1}$ US Energy Information Agency, "US Gulf Coast Kerosene-type Jet Fuel Spot Price FOB”, http://www.eia.gov/

${ }^{2}$ Deutsche Lufthansa AG, ”Annual Report 2011”, http://investor-relations.lufthansa.com/en/finanzberichte/annual-report/

${ }^{3}$ Nicolai, L., "Fundamentals of Aircraft Design", University of Dayton, 1975/1984

4Hepperle, M. "MDO of Forward Swept Wings", KATnet II Workshop, 28-29 January 2008, Braunschweig

${ }^{5}$ Tollmien, W., "Über die Entstehung der Turbulenz”, Nachr. Ges. Wiss. Göttingen, Math. Phys. Klasse, 1929, pp. 21-44.

${ }^{6}$ Schlichting, H., "Zur Entstehung der Turbulenz bei der Plattenströmung”, Nachr. Ges. Wiss. Göttingen, Math. Phys. Klasse, 1933, pp. 182-208.

${ }^{7}$ Schrauf, G., "Status and Perspectives of Laminar Flow," Aeronautical Journal, 2005, vol. 109, No. 1102, pp. 639-644

${ }^{8}$ Maddalon,D., "Simulated Airline Service Flight Tests of Laminar Flow Control with Perforated Suction System" NASA TP 2966, 1990

9Joslin, R.D., "Aircraft Laminar Flow Control", Annu. Rev. Fluid Mech. 1998.30:1-29.

${ }^{10}$ Braslow, A.L., "A History of Suction Type Laminar Flow Control with Emphasis on Flight Research", Monographs in Aerospace History, No 13, NASA History Division, 1999

${ }^{11}$ König, J., Hellstrom, T. "The Clean Sky Smart Fixed Wing Aircraft Integrated Technology Demonstrator: Technology targets and project status" $27^{\text {th }}$ Internat. Congress of the Aeronat. Sciences, Nice, France ICAS 2010.

${ }^{12}$ Drela, M. "Development of the D8 Transport Configuration" AIAA paper 2011-3970, 29th AIAA Applied Aerodynamics Conference, Honolulu, 2011

${ }^{13}$ Breguet L., Aerodynamical efficiency and the reduction of air transport costs, Aeronautical Journal, 26 (1922), pp. 307313.

${ }^{14}$ Redeker, G. und Wichmann, G.: "Forward Sweep - A Favourable Concept for a Laminar Flow Wing", Journal of Aircraft, Vol. 28, pp 97-103. 1991

${ }^{15}$ Weisshaar, T.A.: "Aeroelastic tailoring of forward swept composite wings", Journal of Aircraft, Vol. 18, No. 8, 1981 pp. 669-679

${ }^{16}$ Piening, M.: „Die statische Aeroelastizität des anisotropen Tragflügels“, DGLR Bericht 84-02, 1984

${ }^{17}$ Krone, "Forward Swept Wing Flight Demonstrator" AlAA80-1882, Aircraft and Systems Technology Meeting, Anaheim, California, 1980

${ }^{18}$ Airbus, All about the A320 Family - Technical appendices, May 2009

${ }^{19}$ Airbus, A320 - Airplane Characteristics for Airport Planning, July 1995

${ }^{20}$ Heinze, W. ; Österheld, C. M. ; Horst, P.: Multidisziplinäres Flugzeugentwurfsverfahren PrADO - Programmentwurf und Anwendung im Rahmen von Flugzeug-Konzeptstudien. In: Deutscher Luft- und Raumfahrtkongress, Hamburg, 2001 (DGLR Tagungsband 2001, Band 3 2001-194), S. 1701-1712

${ }^{21}$ Werner-Westphal, C. ; Heinze, W. ; Horst, P.: Multidisciplinary Integrated Preliminary Design Applied to Unconventional Aircraft Configuration. In: Journal of Aircraft 45 (2008), Nr. 2, S. 581-590

${ }^{22}$ Hansen, L. U. ; Heinze,W. ; Horst, P.: Blended Wing Body Structures in Multidisciplinary Pre-Design. In: Journal of Structural and Multidisciplinary Optimization 36 (2008), Nr. 1, S. 93-106

${ }^{23}$ Raymer, D. P.: Aircraft Design: A Conceptual Approach. Third Edition. American Institute of Aeronautics and Astronautics, 1999

${ }^{24}$ Rudolph, P. K. C.: High-Lift Systems on Commercial Subsonic Airliners / National Aeronautics and Space Administration. 1996 (NASA Contractor Report 4746). 
${ }^{25}$ Monner, H., Kintscher, M., Lorkowski, T. and Storm,S.: Design of a Smart Droop Nose as Leading Edge High Lift System for Transportation Aircrafts, AIAA-2009-2128, 17th AIAA/ASME/AHS Adaptive Structures Conference, 2009

${ }^{26}$ Kintscher, Markus and Monner, Hans Peter and Heintze, Olaf (2010) Experimental Testing of a Smart Leading Edge High Lift Device for Commercial Transportation Aircrafts. In: ICAS, Prof. I. Grant, Optimage Ltd., Edinburgh, UK. 27th International Congress of the Aeronautical Sciences , 19.09.2010 - 24.09.2010, Nice, France.

${ }^{27}$ Kintscher, Markus and Wiedemann, Martin and Monner, Hans Peter and Heintze, Olaf and Kühn, Timo (2011) Design of a Smart Leading Edge Device for Low Speed Wind Tunnel Tests in the European Project SADE. International Journal of Structural Integrity, Vol. 2 (Iss: 4), pp. 383-405. Emerald Group Publishing Limited .

${ }^{28}$ Roskam, J.: Airplane Design Part VI: Preliminary Calculation of Aerodynamic, Thrust and Power Characteristics. Lawrence, Kansas, USA : Design, Analysis and Research Corporation, 120 East Ninth Street, Suite 2, Lawrence, Kansas, 66044, USA, 2000

${ }^{29}$ Sanders, K. L.: High Lift Devices, A Weight and Performance Trade-off Methodology. In: 28th Annual Conference, San Francisco, California, Society of Allied Weight Engineers, Inc., May 1969

${ }^{30}$ Streit, T., Wichmann, G., von Knoblauch, F., Campbell, R.: Implications of Conical Flow for Laminar Wing Design and Analysis, AIAA-2011-3808 , 29th AIAA Applied Aerodynamics Conference, Honolulu, Hawaii, June 27-30, 2011

${ }^{31}$ Schrauf, G., “ LILO 2.1 - Users Guide and Tutorial”, GSSC Technical Report, July 2006.

${ }_{32}$ Redeker, G., Horstmann, K.-H., Koester, H., Thiede, P., and Szodruch, J., "Design of a Natural Laminar Flow Glove on a Transport Aircraft", AIAA Paper 90-3043, 1990.

33Redeker, G., Horstmann, K.-H., Dressler, U., and Bieler, H., "Flight Tests with a Natural Laminar Flow Glove on a Transport Aircraft", AIAA Paper 90-3044, 1990.

${ }^{34}$ McGeer, T., "Wing Design for Minimum Drag with Practical Constraints", Journal of Aircraft, Vol. 21, No 11, 1984

35 Smith, P.R. and Srokowski, A.J. "High Aspect Ratio Forward Sweep for Transport Aircraft", AIAA Applied Aerodynamics Conference, 1983, Danvers, MA. AIAA-83- 1832

${ }^{36}$ Gridgen V16 user manual, Pointwise, Inc., 2011, http://www.pointwise.com/gridgen/

${ }^{37}$ Schwammborn, D., Gerhold, T., and Heinrich, R., "The DLR TAU-Code: Recent Applications in Research and Industry," Proceedings of the European Conference on Computational Fluid Dynamics (ECCOMAS CFD), Delft, The Netherlands, 2006

${ }^{38}$ Kroll N., Rossow C.-C., Becker K., Thiele F., "The MEGAFLOW Project", Aerospace Science and Technology 4 (2000) pp. 223-237.

${ }^{39}$ Takanashi, S. "Iterative Three-Dimensional Transonic Wing Design Using Integral Equations”, Journal of Aircraft, Vol. 22 No. 8, 1985 pp. 655-660.

${ }^{40}$ Bartelheimer, W., "Ein Entwurfsverfahren für Tragflügel in transsonischer Strömung", Phd Thesis, TU Braunschweig, 1996, DLR Forschungsbericht 96-30.

${ }^{41}$ MD NASTRAN 2010, Design Sensitivity and Optimization, Software Package, MSC.Software Corporation, Santa Ana, CA, 2010

${ }^{42}$ Krimmelbein, N, Krumbein, A.: Automatic Transition Prediction for Three-Dimensional Configurations with Focus on Industrial Application. 40th Fluid Dynamics Conference and Exhibit, 28 June - 1 July 2010, Chicago, Illinois, USA

${ }^{43}$ Arnal, D., "Boundary Layer Transition: Predictions Based on Linear Theory", in Special Course on Progress in Transition Modeling, AGARD Report. 793, 1994

${ }^{44}$ Schrauf, G, Horstman, K.H., Streit, T. Quest, J., "The TELFONA Pathfinder Wing for the Calibration of the ETW Wind Tunnel", KATnet II Conference on Key Aerodynamic Technologies, 2009, Bremen, Germany

${ }^{45}$ Patran Release Guide 2008 r2, http://www.mscsoftware.com/support/prod_support/patran/documentation/, MSC Software Corporation, Santa Ana, CA, 2008. 